\title{
Equidad tributaria horizontal del impuesto a la renta en Chile
}

\section{Claudio A. Agostini, Claudia Martinez A. y Bárbara Flores}

RESUMEN

PALABRAS CLAVE

CLASIFICACIÓN JEL

AUTORES
En este trabajo se estiman los efectos distributivos de la eliminación del tratamiento diferencial de ingresos empresariales respecto de los ingresos individuales en el sistema tributario chileno, así como de eliminar la principal exención vigente en el impuesto al ingreso de las personas: la del ahorro previsional voluntario. En cuanto a esta exención, los resultados muestran que si bien a quienes favorece son mayoritariamente personas de más altos ingresos, su eliminación no aumenta la progresividad del impuesto al ingreso. En el caso de la eliminación del tratamiento tributario favorable a los ingresos corporativos, los efectos distributivos son importantes en magnitud y el impuesto al ingreso se hace significativamente más progresivo. En general, los resultados evidencian que el impuesto al ingreso en Chile es menos progresivo que lo que parece y que hay espacio para que tenga un papel redistributivo relevante en la disminución de la desigualdad en el ingreso.
Exención tributaria, impuesto a la renta, ahorros, política fiscal, distribución del ingreso, Chile

H24, D31

Claudio A. Agostini es profesor titular en la Escuela de Gobierno de la Universidad Adolfo Ibáñez. claudio.agostini@uai.cl

Claudia Martínez A. es profesora asistente del Departamento de Economía de la Universidad de Chile. cmartineza@econ.uchile.cl

Bárbara Flores es investigadora asociada del Centro de Microdatos del Departamento de Economía de la Universidad de Chile.barflore@fen.uchile.cl 


\section{I}

\section{Introducción}

En los últimos 20 años en Chile no ha habido cambios significativos en los niveles de desigualdad, pese al sostenido crecimiento económico y la marcada reducción de la pobreza ${ }^{1}$. Si bien hay evidencia del efecto de las transferencias del gobierno en la disminución de la pobreza y la desigualdad (Agostini y Brown, 2010 y 2011), existen mayores dudas en el debate público respecto del papel que puede jugar la política tributaria en la reducción de la desigualdad en el ingreso.

La evidencia para los Estados Unidos de América denota que efectivamente una reforma tributaria que sea neutral desde el punto de vista de la recaudación, puede lograr que el impuesto al ingreso sea más progresivo y reducir la desigualdad del ingreso. Por ejemplo, sobre la base de datos de la Encuesta de Gastos de los Consumidores en 1994, Metcalf (1999) señala que una reforma tributaria en que se reemplaza el impuesto progresivo al ingreso en los Estados Unidos de América por un impuesto parejo a las ventas (equivalente al impuesto al valor agregado (IVA)) que recauda lo mismo, es altamente regresiva. Específicamente, un impuesto a las ventas del $16,5 \%$, que reemplaza completamente al impuesto al ingreso vigente en 1998, disminuye el índice de Suits de 0,202 (un impuesto progresivo) a -0,228 (un impuesto regresivo). En forma similar, Altshuler, Harris y Toder (2010) estiman para dicho país los efectos distributivos de una reforma neutral respecto de la recaudación que reduce los impuestos corporativos (una reducción regresiva) y simultáneamente sube los impuestos individuales a las ganancias de capital y los dividendos (un aumento progresivo). El efecto neto de la reforma es progresivo y aminora la desigualdad del ingreso después de impuestos.

Incluso un impuesto plano con un nivel de exención puede ser progresivo y disminuir la desigualdad

$\square$ Claudia Martínez A. y Bárbara Flores agradecen el financiamiento proporcionado por la Iniciativa Científica Milenio del Ministerio de Economía, Fomento y Turismo al Centro de Microdatos, a través del Proyecto NS100041.

${ }^{1}$ Entre 1990 y 2009, el producto interno bruto (PIB) per cápita en Chile creció el 98\% (Indicadores del desarrollo mundial, Banco Mundial). La tasa de pobreza cayó de 38,6\% en 1990 a 15,1\% en 2009. La indigencia también disminuyó marcadamente en este período, de un $13 \%$ a un $3,7 \%$. El coeficiente de Gini, en cambio, era de 0,56 en 1990 y de 0,53 en 2009 (MIDEPLAN, 2010a y 2010b). del ingreso después de impuestos. Por ejemplo, a partir de un modelo de equilibrio general dinámico, con heterogeneidad entre hogares y una función de bienestar social utilitaria, Conesa y Krueger (2006) señalan que el impuesto al ingreso óptimo para los Estados Unidos de América se aproxima a un impuesto plano del 17,2\% y a una deducción fija de 9.400 dólares. De una manera más general, Davies y Hoy (2002) muestran que dados una distribución del ingreso antes de impuestos y un requerimiento de mantener la recaudación constante, la desigualdad después de impuestos disminuirá monotónicamente con la tasa de impuestos bajo un sistema de impuesto plano, en que el nivel de exención personal se ajusta para mantener la recaudación constante.

Finalmente, es importante mencionar que hay evidencia de que existen respuestas relevantes del ingreso reportado ante cambios en los impuestos, en especial para familias de ingresos altos. Lindsey (1987) indica que la reducción en la tasa marginal máxima implementada en la Ley de recuperación económica de 1981 en los Estados Unidos de América (del 70\% al 50\%), se vincula a un aumento considerable en la fracción de impuesto reportado por el $1 \%$ de personas de ingreso más altos. Feenberg y Poterba (1993) muestran también que el incremento estable en la fracción de ingreso bruto tributario recibido por el $0,5 \%$ más rico de la población desde 1970, es consistente con la respuesta de los contribuyentes a las rebajas en la tasa de impuesto por parte de las familias de ingresos altos durante este período. Un análisis de series de tiempo realizado por Slemrod (1996) al intentar aislar las causas de la desigualdad no vinculadas a impuestos, muestra evidencia consistente con aumentos en el ingreso de las familias de altos ingresos producto de rebajas tributarias. Kleven y Schultz (2011), al utilizar datos de Dinamarca, encuentran que la elasticidad del ingreso imponible es mayor en los altos ingresos que en los bajos ingresos.

En el caso particular de Chile, hay varias características del impuesto al ingreso que pueden explicar el papel limitado que este gravamen ha jugado en la reducción de la desigualdad (Engel, Galetovic y Raddatz, 1999). El impuesto al ingreso representa alrededor de un tercio de la recaudación tributaria total y, a pesar de que en él se incorporan en forma integrada los ingresos de todas las distintas fuentes, trata de manera distinta 
a los ingresos de las personas naturales con respecto a los ingresos corporativos. Los ingresos provenientes de las utilidades de las empresas pagan solo un impuesto del $17 \%$, mientras las utilidades no son distribuidas a los dueños ${ }^{2}$. Algunos tipos de empresas pequeñas ni siquiera pagan impuesto a las utilidades mientras estas no se distribuyan ${ }^{3}$. Cuando las utilidades se distribuyen, los impuestos ya pagados a las utilidades se consideran un crédito para efectos del impuesto al ingreso de las personas ${ }^{4}$. Por ejemplo, si una empresa tiene utilidades por 100 pesos, debe pagar 17 pesos en impuestos corporativos. Supongamos que la empresa posteriormente distribuye 50 pesos en dividendos a uno de los dueños, y esa persona al sumar todos sus ingresos -incluidos los dividendos - debe pagar 20 pesos en impuestos a los ingresos personales. Sin embargo, tiene como crédito para el pago de sus impuestos personales el impuesto que pagó la empresa, debiendo pagar finalmente solo 11,5 pesos $=(\$ 20-0,5 * \$ 17)$.

$\mathrm{Si}$ todas las utilidades se distribuyeran, este mecanismo no generaría ningún problema de equidad tributaria horizontal. No obstante, los datos del Servicio de Impuestos Internos (SII) señalan que menos del 30\% de las utilidades de las empresas son distribuidas cada año (Jorrat, 2009).

Además, existen dos regímenes tributarios especiales bajo los cuales las utilidades de las empresas pagan impuestos solo cuando son distribuidas 5 . El objetivo

\footnotetext{
2 Con el objeto de financiar el plan de reconstrucción después del terremoto de 2010, la tasa del impuesto subió temporalmente al $20 \%$ en 2011 y al $18,5 \%$ en 2012 . Luego de un extenso debate, el Congreso Nacional aprobó un proyecto de ajuste tributario enviado por el Ejecutivo, donde se establece una tasa del $20 \%$ que comenzará a regir a partir de 2013 .

3 El $60 \%$ de las empresas se encuentran bajo el régimen general de base tributaria por utilidades devengadas y el otro $40 \%$ tiene un régimen especial sobre la base de utilidades retiradas o renta presunta (Jorrat, 2009).

${ }^{4}$ Contrariamente al caso de Chile, en los Estados Unidos de América, por ejemplo, las utilidades de las empresas pagan primero impuestos corporativos y luego sus dueños pagan un impuesto personal sobre los dividendos percibidos de la empresa, sin que reciban un crédito por los impuestos corporativos ya pagados. Una fracción de las utilidades retenidas también tributa una segunda vez cuando los dueños de la empresa obtienen ganancias de capital provenientes de esas utilidades retenidas.

5 Artículos 14 bis y 14 ter de la Ley sobre Impuesto a la Renta. Bajo el régimen tributario del artículo 14 bis las empresas pagan impuestos solo sobre la base de retiros. Los requisitos para acceder a este sistema de tributación son tener ingresos anuales por menos de 5.000 uTM (hasta el año 2008 eran 3.000 UTM) y un capital inicial menor de 1.000 UTM (era de 200 UTM hasta el año 2008). Bajo el régimen tributario del artículo 14 ter las empresas tributan sobre la base de su flujo de caja y se permite llevar contabilidad simplificada y deducir como gasto las inversiones e inventarios. Los requisitos son ser contribuyente de IVA, tener ingresos anuales por menos de 5.000
}

de estos regímenes especiales es proveer de liquidez a pequeñas empresas ${ }^{6}$. Sin embargo, también pueden ser utilizados por pequeñas empresas de inversión, cuya propiedad corresponde a un pequeño grupo familiar y sus miembros tienen la posibilidad de hacer pasar sus ingresos personales como ingresos empresariales. La evidencia empírica resalta que el 52\% de todas las utilidades retenidas en Chile en el año 2006 se encuentran precisamente en este tipo de empresas familiares o matrimoniales pertenecientes al decil de ingresos más altos, que utilizan estos regímenes tributarios especiales (Jorrat, 2009)7.

Una segunda característica particular del sistema tributario chileno es el alto nivel de ingreso exento de impuestos, que sobrepasa con creces el salario promedio. Este nivel tan alto, junto con la asimétrica distribución del ingreso, se traduce en que pocas personas paguen impuestos al ingreso. En 2009, un 82,7\% de los contribuyentes tenían ingresos inferiores al nivel de exención $\mathrm{y}$, por lo tanto, no tuvieron que pagar impuesto al ingreso. En consecuencia, todas las exenciones e incentivos tributarios que existen en el impuesto al ingreso benefician directamente al $17 \%$ de las personas de ingresos más altos en el país. A pesar de ello, y de la ostensible preocupación pública por los niveles de desigualdad, en los últimos años ha aumentado el número de exenciones tributarias en el impuesto al ingreso con distintos fines específicos (incentivar el ahorro general y el ahorro previsional, la adquisición de viviendas, la compra de automóviles híbridos, la compra e instalación de paneles solares en viviendas, entre otros) y en el parlamento hay múltiples propuestas de incentivos y exenciones adicionales a las ya existentes.

De acuerdo con estadísticas del SII (DIPRES, 2009), el gasto tributario representaba en 2010 alrededor de un $5,72 \%$ del producto interno bruto (PIB) y el componente principal correspondía al impuesto al ingreso $(4,90 \%$ del PIB). La mayor fuente de gasto tributario es la postergación del pago de impuestos $(4,03 \%)$, lo que representa prácticamente el mismo monto total recaudado por el impuesto al ingreso, de tal modo que eliminar dicha postergación podría potencialmente duplicar incluso la recaudación del impuesto al ingreso. Dentro de los

UTM (el promedio de los últimos 3 ejercicios era de 3.000 UTM hasta el año 2008) y un capital inicial menor de 6.000 UTM.

${ }^{6}$ Las empresas con ventas anuales por menos de 127 millones de pesos (alrededor de 270.000 dólares) o con capital menor de 7,5 millones de pesos (equivalentes a 16.600 dólares) pueden utilizar estos regímenes especiales.

${ }^{7} \mathrm{El} 77,9 \%$ de todas las utilidades retenidas pertenece al decil de más altos ingresos. 
distintos mecanismos tributarios para postergar el pago del impuesto al ingreso, el más relevante en magnitud es precisamente el de las utilidades no retiradas $(2,01 \%)$ y los retiros reinvertidos antes de 20 días $(0,94 \%)$.

En este trabajo se describe y analiza la repercusión que tienen en la progresividad del impuesto al ingreso la exención al ahorro previsional voluntario (APV) y la postergación del pago de impuestos de los ingresos corporativos. Para ello se utilizan datos del sir y de la Encuesta de Caracterización Socioeconómica Nacional (CASEN). Tanto el APV como la postergación tributaria de las utilidades de empresas fueron discutidos como fuente potencial de ingresos para financiar la reconstrucción después del terremoto de 2010, sin que hubiera acuerdo para eliminar estos beneficios tributarios.

Los resultados denotan que el APV, si bien es utilizado por las personas de más altos ingresos, repercute poco en la disminución de la progresividad del impuesto al ingreso. Sin embargo, los efectos distributivos de la postergación del pago de impuestos sobre las utilidades de las empresas sí son importantes. Un cambio en la base tributaria desde "utilidades retiradas" a "utilidades devengadas", manteniendo el crédito del impuesto corporativo para efectos del pago del impuesto al ingreso personal, incrementa de forma significativa la progresividad del impuesto al ingreso y la tasa de impuestos media pagada por las personas de más altos ingresos.

En estudios previos se han hallado resultados disímiles con respecto a esto último. Por una parte, Engel, Galetovic y Raddatz (1999) encuentran que este tipo de cambios no modifican la escasa repercusión de los impuestos en la distribución del ingreso. Su conclusión es que solo el gasto social focalizado puede ser efectivo en la redistribución de ingresos. La principal razón radicaría en que los ingresos de todos los deciles son muy bajos y la tasa media de impuestos es de apenas un $3 \%$.
Cabe subrayar que en el estudio de estos autores se usan datos de la encuesta CASEN, por lo que los ingresos de los deciles más altos están subreportados, lo que subestima el efecto distributivo del impuesto al ingreso. Además, se asume que las utilidades retenidas de las empresas no se distribuyen entre sus dueños, lo que también limita el potencial poder redistributivo del impuesto al ingreso. Por otra parte, Cantallops, Jorrat y Scherman (2007), mediante datos del sII, evidencian que una reforma tributaria —neutral en términos de recaudación-que elimina las exenciones del impuesto al ingreso y los regímenes especiales de impuesto a las utilidades de las empresas y reduce el impuesto al valor agregado (IVA), es una reforma que acrecienta la progresividad del sistema tributario e influye considerablemente en mejorar la distribución del ingreso en Chile. En este caso, la tributación de las utilidades retenidas por parte de sus dueños juega un papel fundamental en el resultado.

En el presente trabajo se utilizan datos del sis para analizar los efectos de la exención al APV y datos de la encuesta CASEN para examinar el efecto de un cambio en la base del impuesto a las utilidades de las empresas. En este último análisis, si bien se utilizan datos equivalentes a los empleados por Engel, Galetovic y Raddatz (1999), en las simulaciones se considera explícitamente la distribución de utilidades a los dueños de las empresas.

El artículo continúa de la siguiente forma. En la sección II se describe con mayor detalle el impuesto al ingreso en Chile, con especial énfasis en la exención tributaria existente para el APV. En la sección III se presentan las dos bases de datos utilizadas en el análisis empírico posterior. En la sección IV se analiza el efecto distributivo de las principales exenciones existentes y del mecanismo de postergación tributaria de las utilidades de las empresas. Finalmente, en la sección $\mathrm{V}$ se resumen los principales resultados y conclusiones. 


\section{II}

\section{El sistema tributario chileno}

\section{Descripción general}

La recaudación tributaria representa la principal fuente de recursos para el Estado chileno y genera alrededor del 70\% de sus ingresos. En 2010 los ingresos tributarios netos representaron el 13,6\% del $\mathrm{PIB}^{8}$. De esta fracción, el 53,6\% lo genera el impuesto al valor agregado (IVA); un 10,4\% lo aportan los impuestos específicos a bienes (combustibles, alcohol, cigarrillos y tabaco); el 32,2\% proviene del impuesto al ingreso y el restante $3,8 \%$ de los impuestos a los actos jurídicos y al comercio exterior.

El impuesto al ingreso tiene una tasa única permanente del $20 \%$ a partir de $2013^{9}$ para las utilidades de las empresas y una estructura de siete tasas de impuesto marginal más un nivel de exención para el ingreso de las personas. Tal como ya se mencionó, la tasa de impuestos corporativos no determina la carga tributaria final de las utilidades de las empresas, ya que además incorpora el impuesto a los ingresos de las personas. El impuesto corporativo es un gravamen que actúa como retención del impuesto a los ingresos personales, y cuando las utilidades se distribuyen entre los accionistas o dueños de las empresas los dividendos recibidos constituyen parte de la base tributaria del impuesto a las personas, por lo que se suman a todos los otros ingresos percibidos y la persona tributa de acuerdo con el tramo impositivo en que se encuentre según su nivel de ingresos. Para tales efectos, los impuestos corporativos pagados previamente por la empresa constituyen un crédito contra el pago del impuesto personal. En ese sentido, el impuesto corporativo actúa solo como retención del futuro impuesto personal a cancelar por parte de los dueños de la empresa. Además, existen dos regímenes tributarios especiales para empresas pequeñas que permiten que sus utilidades tributen solo sobre la base de los retiros que realizan los dueños. En esos casos, no existe la retención del 17\% sobre las utilidades devengadas de cada año. El gasto tributario por la postergación de impuestos hasta que

\footnotetext{
${ }^{8}$ En 2008 era del $18,5 \%$ y el promedio para el período 2004-2008 fue del $17,4 \%$, lo que implica que la recaudación tributaria fue particularmente baja en 2009.

${ }^{9}$ La tasa del impuesto que era de $17 \%$ hasta el año 2010, fue fijada en forma transitoria en $20 \%$ para el año 2011 y en 18,5\% para el año 2012.
}

las utilidades se distribuyan entre sus dueños se estima en un 2,01\% del PIB para el año 2010 (DIPRES, 2009).

Por otra parte, los siete tramos del impuesto a las personas tienen tasas marginales que van de un $5 \%$ al $40 \%$. El nivel de ingreso exento es tal que el $83,42 \%$ de los contribuyentes no tuvieron que pagar el impuesto en 200910 . Además, un 10,8\% de ellos se encuentran en el primer tramo de ingreso y pagan una tasa marginal de un $5 \%$. De modo que en la práctica, apenas un 5,78\% de los contribuyentes enfrentan una tasa marginal de $10 \%$ o más. Si se considera la tasa marginal máxima de $40 \%$, solo un $0,22 \%$ de quienes tributan se encuentran en ese tramo de ingreso, por lo que si bien la tasa marginal del $40 \%$ puede ser considerada relativamente alta comparada con el resto de los países de América Latina, en la práctica menos de un $1 \%$ de las personas están afectas a ella.

En el gráfico 1 se aprecian las tasas marginales de impuesto de cada tramo y el número total de contribuyentes en cada uno de ellos. Es posible notar que la mayor proporción de contribuyentes enfrentan una tasa marginal de impuesto igual a cero. Por esta sola razón no es sorprendente que en las simulaciones empíricas se constate que el sistema de impuestos al ingreso en Chile no tiene un poder redistributivo importante y que en términos globales el sistema tributario es marginalmente regresivo (Engel, Galetovic y Raddatz, 1999) ${ }^{11}$.

En general, el gobierno puede afectar a la distribución del ingreso por medio de impuestos progresivos y gasto público focalizado. En la práctica, en Chile se ha elegido hacerlo solo por la vía del gasto social y recaudar impuestos en la forma más eficiente posible independientemente de sus efectos distributivos ${ }^{12}$.

\footnotetext{
${ }^{10}$ El nivel de exención fue de 508.302 pesos mensuales en el año tributario 2009, equivalentes a 908 dólares. Este nivel de exención está por sobre el ingreso promedio en Chile que era de 269.921 pesos mensuales, equivalentes a 482 dólares.

11 Según la Ley de Presupuestos 2010, publicada por la Dirección de Presupuestos, la principal fuente de ingresos tributarios es el impuesto al valor agregado (IVA), que en dicho año aportó el $32 \%$ de la recaudación. Considerando este elemento en conjunto con la estructura del impuesto a la renta, no es sorprendente que la estructura tributaria no sea progresiva.

12 En la encuesta CASEN de 2009 se observa que el coeficiente de Gini del ingreso autónomo per cápita es de 0,55 , pero después de las transferencias monetarias del gobierno se reduce a 0,53 .
} 


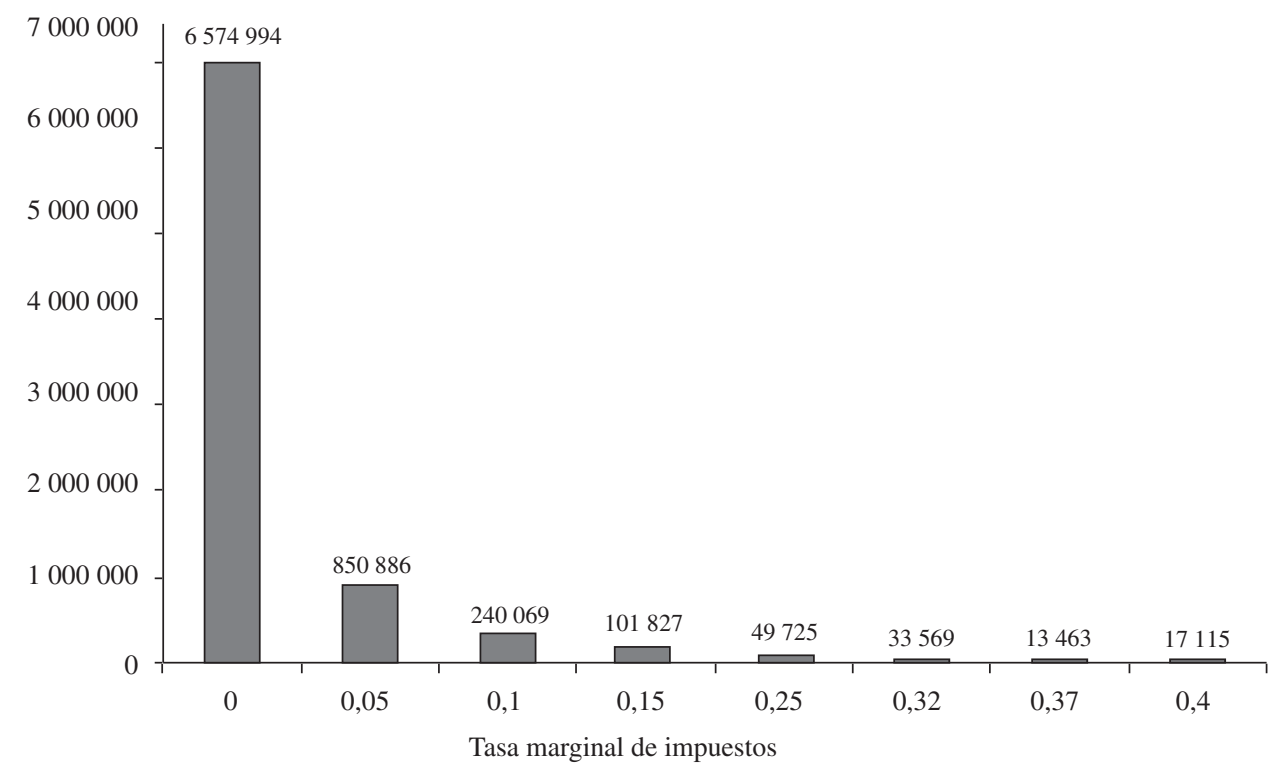

Fuente: elaboración propia sobre la base de datos administrativos del Servicio de Impuestos Internos (SII).

La estructura del impuesto al ingreso en Chile genera una notoria inequidad tributaria horizontal, al otorgar un tratamiento preferencial a las utilidades de las empresas con relación a los ingresos laborales. Es así como dos personas con idéntico nivel de ingresos pueden enfrentar tasas de impuestos muy diferentes. Una persona que solo percibe ingresos laborales paga impuestos con una tasa marginal que puede llegar al $40 \%$, en cambio una persona con ingresos provenientes únicamente de su empresa paga solo un $17 \%$ mientras no haga retiros. Si la empresa está en el régimen especial de utilidades retiradas no paga impuestos hasta que retire dividendos. Obviamente, esta brecha tributaria genera incentivos para crear empresas con el solo propósito de reducir el pago de impuestos, dejando todos los ahorros personales como utilidades retenidas libres de impuesto (o con un impuesto de un $17 \%$ en el caso de empresas grandes).

La inequidad horizontal que se genera sería potencialmente solo temporal y se limitaría a una ganancia financiera por el costo del dinero en el tiempo, ya que una vez que se distribuyen las utilidades de la empresa los dividendos pagan el impuesto al ingreso de acuerdo con el tramo y tasa marginal del ingreso total del dueño de la empresa. En ese sentido, la magnitud de la inequidad se limitaría a la ganancia financiera ocasionada por la postergación del pago de impuestos. Sin embargo, Jorrat
(2009) muestra que menos de un tercio de las utilidades son distribuidas cada año y que existen muchas formas legales de retirar las utilidades de las empresas sin que nunca tributen, por lo que la inequidad horizontal no solo permanece en el tiempo, sino que es de una magnitud bastante mayor ${ }^{13}$.

Sin duda, una segunda fuente de inequidad horizontal es la evasión tributaria (Slemrod y Yitzhaki, 2002; Slemrod, 2007), ya que una persona que evade paga menos impuestos que una persona con iguales ingresos que no evade. En Chile, la evasión tributaria se estima en un 30\% respecto del impuesto a las utilidades de las empresas y en el $46 \%$ con relación al impuesto al ingreso personal. En este último caso, el $92 \%$ de la evasión proviene de la distribución de utilidades y dividendos a los dueños de las empresas (Jorrat, 2009).

\footnotetext{
13 Una forma de retirar utilidades sin que tributen es mediante la generación de gastos en la empresa, que en realidad corresponden a consumo del hogar, por ejemplo, a través de la compra de automóviles y camionetas $4 \mathrm{x} 4$ o computadores. Otra alternativa consiste en generar artificialmente deudas con empresas relacionadas o efectuar la compra de todas las acciones de una empresa relacionada en un valor que produce una ganancia de capital que está exenta de impuestos. Además, es posible incorporar como socios a hijos mayores de 18 años, quienes si no trabajan pueden retirar cada uno hasta el monto exento del impuesto al ingreso (alrededor de 6 millones de pesos anuales).
} 
Al mismo tiempo, el sistema tributario chileno, al igual que en la mayoría de los países, tiene exenciones y créditos tributarios con objetivos múltiples ${ }^{14}$. Sin embargo, conviene tener en cuenta que dado el alto nivel de exención en el impuesto al ingreso personal, estas exenciones generan efectos distributivos solo en el $17 \%$ de las personas de mayores ingresos, que son quienes pueden beneficiarse del tratamiento tributario preferencial. En este trabajo, el foco está puesto en la exención que beneficia al ahorro previsional, conocido como ahorro previsional voluntario (APV), que produce un gasto tributario equivalente a un $0,06 \%$ del PIB (véase el cuadro 1).

\section{Ahorro previsional voluntario (APV)}

El objetivo principal de esta exención es aumentar el ahorro previsional de las personas por medio de contribuciones voluntarias a sus cuentas de capitalización individual. Chile tiene un sistema de pensiones basado en cuentas individuales de capitalización y ahorro obligatorio, que consiste en contribuciones mensuales obligatorias de un $10 \%$ del salario con un tope máximo de 64,7 Unidades de Fomento (UF) ${ }^{15}$. Las personas pueden

14 En el cuadro 1 se muestran las fuentes principales de gasto
tributario en 2010 .
15 Las administradoras de fondos de pensiones (AFP) cobran comisiones
por administrar los fondos previsionales obligatorios. Para una
descripción del sistema, véase Superintendencia de Pensiones (2003). elegir una administradora de fondos de pensiones (AFP) y el riesgo del portfolio de activos donde se invierten sus fondos. Este ahorro obligatorio está exento del pago de impuesto a los ingresos personales; de hecho, forma parte del salario bruto de un trabajador y ni siquiera se considera en la base del impuesto.

En el año 2002, la baja tasa de reemplazo de los pensionados con este sistema (39\% en mujeres y 58\% en hombres de acuerdo con Bernstein, Larraín y Pino, (2006), condujo a la creación de un incentivo tributario para contribuciones voluntarias adicionales a las cuentas individuales de capitalización: el ahorro previsional voluntario (APV). Desde octubre de 2008, las personas que usen este beneficio pueden elegir entre dos alternativas tributarias. La primera consiste en la exención de impuesto de la contribución voluntaria en el momento de hacerla, es decir, el monto de APV se resta de la base imponible. Los aportes de cotizaciones voluntarias se rebajan de la base imponible del impuesto a la renta hasta un máximo de 50 uf mensuales (con un tope de 600 Uf anuales). Posteriormente, cuando se retiran los fondos, estos pasan a formar parte de la base del impuesto al ingreso en el año en que se haga el retiro. $\mathrm{Si}$ el retiro se realiza con posterioridad a la edad de jubilación, la tasa de impuestos es la asociada al tramo correspondiente en la estructura regular del impuesto al ingreso personal. Si el retiro se realiza antes de la edad de jubilación, se paga un impuesto adicional de entre un $3 \%$ y un $7 \%$, penalizando así un uso de los fondos distinto al previsional.

CUADRO 1

Gasto tributario 2010 en Chile: partidas más relevantes

\begin{tabular}{lcc}
\hline Gasto tributario & Millones de pesos & Porcentaje del PIB \\
\hline Rentas empresariales retenidas no pagan impuesto & 3660 & 2,01 \\
Tratamiento de las rentas del sistema de fondos de pensiones & 1723 & 0,94 \\
Retiros reinvertidos antes de 20 días no pagan impuesto & 646 & 0,35 \\
Otras diferencias temporarias & 400 & 0,22 \\
Crédito especial para la construcción de viviendas & 377 & 0,21 \\
Depreciación acelerada & 332 & 0,18 \\
Exención del IVA a las prestaciones de salud & 290 & 0,16 \\
Rentas de arrendamientos de viviendas acogidas al DFL 2 & 250 & 0,14 \\
Exención del IVA a establecimientos de educación & 239 & 0,13 \\
Cuotas leasing & 228 & 0,12 \\
Tratamiento especial de las cotizaciones voluntarias, depósitos & 54 & 0,06 \\
convenidos y del ahorro previsional Voluntario (APV) & 5 \\
\hline
\end{tabular}

Fuente: Subdirección de Estudios, Servicio de Impuestos Internos (SII), septiembre de 2009.

Notas:

1. Incluye declaraciones en moneda extranjera.

2. Excluye partidas de gasto negativo y partidas correspondiente al promedio observado.

3. Considera un tipo de cambio de 522,46 pesos por dólar, correspondiente al promedio observado para 2008. 
La segunda alternativa, a diferencia de la primera, no exime al APV de la base tributaria en el año en que se realiza el aporte. El beneficio se produce cuando los fondos son retirados, momento en que solo el retorno del ahorro pasa a formar parte de la base del impuesto al ingreso personal. Además, la persona recibe una contribución de un $15 \%$ por parte del Estado con un tope de 6 Unidades Tributarias Mensuales (UTM) por año.

Las dos alternativas existentes de incentivo tributario apuntan a incrementar el ahorro previsional de dos tipos distintos de contribuyentes. La primera alternativa favorece a las personas que tienen que pagar impuestos al ingreso personal el año en que hacen la contribución previsional voluntaria. La segunda alternativa favorece a los individuos que están exentos del pago de impuestos al ingreso personal en el momento en que contribuyen voluntariamente a su cuenta de fondos previsionales. Esta segunda alternativa fue creada el año 2008, seis años después de la creación del APV.

Dado que las tasas marginales del impuesto al ingreso de las personas aumentan con el nivel de renta, el beneficio tributario del APV también se incrementa con ella hasta el tope máximo. Por lo tanto, si comparamos personas con distintos niveles de ingreso, pero con el mismo monto de APV, el beneficio tributario que recibe cada uno como fracción de su renta es precisamente la tasa marginal que enfrenta, siempre y cuando el APV sea menor al tope máximo y la exención no induzca al individuo a cambiarse a un tramo inferior de impuesto. Por ejemplo, si el APV es de 200.000 pesos chilenos (alrededor de 450 dólares), el ahorro impositivo es de 10.000 pesos para una persona en el tramo cuya tasa de impuesto marginal es de un 5\% y de 80.000 pesos para una persona que se halla en el tramo cuya tasa es del $40 \%$.

Obviamente, una persona que no paga impuesto al ingreso porque se encuentra exenta, como es el caso del $82 \%$ de los trabajadores en Chile, no se beneficia de esta exención tributaria. Las personas exentas sí obtienen un beneficio tributario según la segunda alternativa de incentivo descrita anteriormente, pero ello ocurre una vez que se jubilan y no cuando invierten en APV.

De acuerdo con estadísticas de la Superintendencia de Pensiones, en diciembre del año 2010 existían 827.574 cuentas de APV en el sistema, con un saldo acumulado de mil millones 817 mil 424 pesos. El gasto tributario asociado a estas cuentas se estima en un $0,8 \%$ de la recaudación del impuesto personal al ingreso.

\section{III}

\section{Análisis empírico}

Para el análisis empírico del efecto distributivo de la exención tributaria al APV y el tratamiento preferencial de las utilidades de las empresas se utilizan dos fuentes de datos distintas.

En primer lugar, en este trabajo se emplean datos provistos por el sII, especialmente producidos para este estudio. El sII tiene como política no proveer datos a nivel individual de contribuyentes, sino solo a nivel muy agregado de recaudación por tipo de impuesto ${ }^{16}$. Sin embargo, para los efectos de este estudio el sII aportó datos respecto del año 2007, bastante más desagregados, calculando ingresos antes de impuestos y las distintas exenciones utilizadas por los contribuyentes para 1.000 cuantiles de ingreso. Estos datos permiten analizar en detalle los efectos en la progresividad del impuesto de las

\footnotetext{
16 El SII ha señalado por mucho tiempo que la ley chilena le impide entregar datos individuales aunque sean completamente innominados.
}

principales exenciones y créditos tributarios existentes relativos al impuesto al ingreso personal.

En segundo lugar, se utiliza la encuesta de Caracterización Socioeconómica Nacional (CASEN) del año $2003^{17}$. En los datos de esta encuesta se incluyen características socioeconómicas de los miembros de cada hogar, características de la vivienda, principales bienes durables en el hogar y las distintas fuentes de ingreso, incluidas las transferencias recibidas del Estado.

La encuesta CASEN 2003 fue realizada por la Universidad de Chile para el Ministerio de Planificación y Cooperación (MIDEPLAN) ${ }^{18}$, pero los datos fueron ajustados posteriormente por la Comisión Económica para América Latina y el Caribe (CEPAL) teniendo las cuentas

\footnotetext{
17 Las encuestas CASEN de los años 2006 y 2009 aún no han sido entregadas para uso público con todas las variables de ingresos desagregadas que se necesitan para efectos de este estudio. ${ }^{18}$ En octubre de 2011 pasó a llamarse Ministerio de Desarrollo Social.
} 
nacionales como referencia. En los ajustes se consideran principalmente los problemas generados por la falta de datos de ingreso en algunos hogares y la sub o sobredeclaración de algunas fuentes de ingreso en la muestra ${ }^{19}$.

En la encuesta CASEN se utiliza un método de muestreo aleatorio de etapas múltiples con estratificación. En la primera etapa, el país se divide entre áreas rurales y urbanas en cada una de las 13 regiones y las unidades de muestreo primario son seleccionadas con probabilidades proporcionales a la población. En la segunda etapa, dada la estratificación, se seleccionan los hogares de tal forma que todos tengan la misma probabilidad de ser elegidos en la muestra ${ }^{20}$.

En el cuadro 2 se aprecia una descripción estadística de los datos de la encuesta CASEN de 2003. En la muestra expandida hay 6.921.064 individuos con ingresos positivos ${ }^{21}$. El ingreso autónomo promedio —en que no se consideran transferencias monetarias del Estado_- es de 311.803 pesos (equivalentes a 660 dólares). El ingreso antes de impuestos

${ }^{19} \mathrm{Si}$ bien los ajustes realizados por la CEPAL pueden generar algún grado de sesgo en los datos, existe evidencia de que esto no ocurre (Contreras y Larrañaga, 1999). Por otra parte, los datos sin ajustar no están disponibles por lo que no es posible utilizarlos.

${ }^{20} \mathrm{El}$ marco metodológico se encuentra disponible en la página web: http://www.mideplan.cl/casen/pdf/Metodologia_\%202003.pdf

${ }^{21}$ En la muestra no expandida hay 68.153 hogares, en los que viven 257.077 personas. se calcula tomando como base el ingreso autónomo de cada individuo calculado en la encuesta, pero haciendo ajustes que permitan replicar la base del impuesto al ingreso. Para ello es necesario considerar componentes del ingreso autónomo que no forman parte de la base del impuesto al ingreso personal, como el valor del autoconsumo, el arriendo de vivienda imputado en el caso de vivienda propia, el ingreso por arriendos y los gastos presuntos por ingresos como trabajador independiente 22 .

Una vez calculado el ingreso de cada individuo antes de impuestos es posible aplicar la estructura de tasas marginales por tramo de ingreso y estimar el pago de impuestos correspondiente a cada uno. La tasa de impuesto promedio de impuesto a las personas en la encuesta CASEN es de $0,5 \%$, ligeramente inferior a la tasa promedio de $0,6 \%$ en los datos del sII. Dado que la muestra es representativa a nivel nacional y en el promedio calculado se considera la estructura de la muestra, la diferencia entre las dos tasas de impuesto promedio puede reflejar evasión y elusión tributaria en el impuesto al ingreso o también el hecho de que las personas de más altos ingresos generalmente no

${ }^{22} \mathrm{El}$ ingreso antes de impuestos utilizando la CASEN se calcula como: Ingreso Autónomo-AutoConsumo-Arriendo Imputado-Ingresos No Renta-Gastos Presuntos (hasta el tope permitido para trabajadores independientes).

CUADRO 2

Estadísticas descriptivas sobre la base de la encuesta CASEN de 2003

\begin{tabular}{|c|c|c|c|c|c|}
\hline Variable & $\begin{array}{c}\mathrm{N}^{\mathrm{o}} \mathrm{de} \\
\text { observaciones }\end{array}$ & Media & $\begin{array}{l}\text { Desviación } \\
\text { estándar }\end{array}$ & Mínimo & Máximo \\
\hline Ingreso autónomo & 6921064 & 311803 & 757864 & 46 & 80000000 \\
\hline Autoconsumo & 6921064 & 1070 & 9773 & 0 & 823334 \\
\hline Autosuministro & 6921064 & 1042 & 15198 & 0 & 2964000 \\
\hline Valor locativo & 6921064 & 31750 & 45663 & 0 & 2185000 \\
\hline Arriendo de propiedades & 6921064 & 4416 & 179642 & 0 & 60000000 \\
\hline Gasto presunto (honorarios) & 6921064 & 3432 & 28431 & 0 & 2400000 \\
\hline Intereses y dividendos & 6921064 & 91 & 3670 & 0 & 594780 \\
\hline \multicolumn{6}{|l|}{ Ingreso antes de impuestos con } \\
\hline autorreporte de intereses y dividendos & 6921064 & 3239053 & 8365931 & 324 & 666000000 \\
\hline \multicolumn{6}{|l|}{ Ingreso antes de impuestos con } \\
\hline imputación de intereses y dividendos & 6921064 & 9259341 & 227000000 & 324 & 39600000000 \\
\hline \multicolumn{6}{|l|}{ Ingreso después de impuestos con } \\
\hline \multicolumn{6}{|l|}{ Tasa de impuesto promedio (autorreporte } \\
\hline de intereses y dividendos) & 6921064 & 0005 & 0022 & 0 & 0385 \\
\hline \multicolumn{6}{|l|}{ Tasa de impuesto promedio (imputación } \\
\hline de intereses y dividendos) & 6921064 & 0008 & 0037 & 0 & 0400 \\
\hline
\end{tabular}

Fuente: elaboración propia sobre la base de la encuesta de Caracterización Socioeconómica Nacional (CASEN), 2003. 
Estadísticas descriptivas sobre la base de datos administrativos del SII

\begin{tabular}{|c|c|c|c|c|c|}
\hline Variables & $\begin{array}{c}\mathrm{N}^{\mathrm{o}} \mathrm{de} \\
\text { observaciones }\end{array}$ & Media & $\begin{array}{l}\text { Desviación } \\
\text { estándar }\end{array}$ & Mínimo & Máximo \\
\hline $\mathrm{N}^{\mathrm{o}}$ de contribuyentes & 1000 & 7422 & 0 & 7422 & 7423 \\
\hline Retiros (Arts. 14 y 14 bis) & 1000 & 3790000000 & 53300000000 & 0 & 1670000000000 \\
\hline Dividendos (Arts. 14 y 14 bis) & 1000 & 268000000 & 2460000000 & 0 & 70600000000 \\
\hline Gastos rechazados & 1000 & 970000000 & 13600000000 & 0 & 421000000000 \\
\hline Rentas presuntas & 1000 & 296000000 & 675000000 & 0 & 13400000000 \\
\hline Rentas por contabilidad simplificada (Art. 14 ter) & 1000 & 247000000 & 883000000 & 0 & 18100000000 \\
\hline Honorarios y directores & 1000 & 2880000000 & 6750000000 & 0 & 125000000000 \\
\hline $\begin{array}{l}\text { Rentas capitales mobiliarios, retiros de } \\
\text { excedentes de libre disposición y ganancias } \\
\text { de capital }\end{array}$ & 1000 & 157000000 & 785000000 & 0 & 19600000000 \\
\hline $\begin{array}{l}\text { Rentas exentas de impuesto global } \\
\text { complementario }\end{array}$ & 1000 & 36600000 & 344000000 & 0 & 10300000000 \\
\hline Rentas art. 42 (sueldos, pensiones, y otros) & 1000 & 8500000000 & 27100000000 & 0 & 440000000000 \\
\hline Incremento rentas de sociedad & 1000 & 692000000 & 10400000000 & 0 & 325000000000 \\
\hline Pago de impuesto de sociedades y propiedad & 1000 & 962000000 & 13100000000 & 0 & 405000000000 \\
\hline Pérdidas de capital & 1000 & 65000000 & 254000000 & 0 & 5750000000 \\
\hline Cotización previsional empresario o socio & 1000 & 2774558 & 16300000 & 0 & 286000000 \\
\hline Beneficios hipotecarios & 1000 & 429000000 & 1020000000 & 0 & 6150000000 \\
\hline $\begin{array}{l}\text { Fondos mutuos y ahorro previsional } \\
\text { voluntario (APV) }\end{array}$ & 1000 & 38300000 & 186000000 & 0 & 2230000000 \\
\hline Base de impuesto global complementario & 1000 & 14500000000 & 46700000000 & 0 & 826000000000 \\
\hline Fondos mutuos & 1000 & 255079 & 2023752 & 0 & 52600000 \\
\hline Ahorro previsional voluntario (APV) & 1000 & 37900000 & 184000000 & 0 & 2220000000 \\
\hline 57 bis (ahorro neto positivo) & 1000 & 5185888 & 38900000 & 0 & 957000000 \\
\hline Impuesto global complementario & 1000 & -59100000 & 3070000000 & -3230000000 & 89500000000 \\
\hline Base imponible & 1000 & 31500000000 & 105000000000 & 48236 & 2980000000000 \\
\hline Base imponible sin deducción del APV & 1000 & 31500000000 & 105000000000 & 48236 & 2980000000000 \\
\hline Impuesto calculado sobre base imponible & 1000 & 2240000000 & 35600000000 & 0 & 1100000000000 \\
\hline $\begin{array}{l}\text { Impuesto calculado sobre base imponible sin } \\
\text { deducción del APV }\end{array}$ & 1000 & 2250000000 & 35600000000 & 0 & 1110000000000 \\
\hline Tasa de impuesto promedio base imponible & 1000 & 000626 & 002377 & 000000 & 037090 \\
\hline $\begin{array}{l}\text { Tasa de impuesto promedio base imponible } \\
\text { sin deducción del APV }\end{array}$ & 1000 & 000627 & 002384 & 000000 & 037092 \\
\hline Exención del APV & 1000 & 37900000 & 184000000 & 0 & 2220000000 \\
\hline
\end{tabular}

Fuente: base de datos administrativos del Servicio de Impuestos Internos (SII).

Nota: bajo el régimen tributario del artículo 14 ter las empresas tributan sobre la base de su flujo de caja y se permite llevar contabilidad simplificada y deducir como gasto las inversiones e inventarios. Los requisitos son ser contribuyente de IVA, tener ingresos anuales por menos de 5.000 uTM (el promedio de los últimos 3 ejercicios era de 3.000 UTM hasta el año 2008) y un capital inicial menor de 6.000 UTM.

están representadas en la encuesta ${ }^{23}$. La tasa promedio máxima en la encuesta CASEN es del 38,5\%, superior a la tasa promedio máxima del $37,09 \%$ calculada con los datos del siI. Si las utilidades de las empresas formaran parte de la base del impuesto al ingreso personal independientemente de si se retiran o no, la tasa promedio de impuestos aumentaría de $0,5 \%$ a $0,78 \%$ y la tasa promedio máxima se acrecentaría del 38,5\% al 39,9\%.

En el cuadro 3 se muestran estadísticas descriptivas de los datos tributarios del SII. Hay 7.422 ó 7.423

23 Obviamente, podría ser un simple error de muestreo. contribuyentes en cada cuantil de ingresos. Los datos consisten en las declaraciones de impuestos agregadas para cada uno de los 1.000 cuantiles de ingreso antes de impuestos. La tasa promedio de impuesto al ingreso personal pagado, para el total de contribuyentes en Chile, es de 0,626\%. La tasa máxima es del 37,09\% en el último cuantil de ingreso, es decir, respecto del $0,1 \%$ de contribuyentes de más altos ingresos en el país. La baja tasa promedio se explica obviamente por el hecho de que la gran mayoría de los contribuyentes tienen una tasa de $0 \%$. La tasa promedio aumenta a $0,627 \%$ cuando se elimina el beneficio tributario del APV. 


\section{IV}

\section{Resultados empíricos}

Tal como se discutió en la descripción del sistema tributario chileno correspondiente al ingreso, existen dos fuentes principales de reducción de la progresividad del impuesto al ingreso. La primera es el tratamiento tributario preferencial de las utilidades retenidas, especialmente en el caso de empresas pequeñas que tributan solo sobre la base de retiros. Ello genera incentivos para hacer pasar los ingresos personales como ingresos corporativos y así postergar o incluso eludir el pago de impuestos personales. La segunda es el conjunto de incentivos tributarios al ahorro y la inversión de las personas; esta investigación se centra en particular en los beneficios tributarios para el APV.

Idealmente, se usarían datos del sII para analizar el efecto de estas dos fuentes principales en la reducción de la progresividad del impuesto. Sin embargo, los datos tributarios del siI solo se entregan en relación con los ingresos personales reportados en el formulario de declaración del impuesto personal. Es así como la información sobre retiros y dividendos corresponde solo a los que han sido distribuidos y no se refiere a las utilidades retenidas. Si bien el sII maneja información sobre las utilidades de cada empresa a través de la declaración del impuesto corporativo, sería necesario asignar las utilidades retenidas de cada empresa a cada uno de sus dueños de acuerdo con la participación de estos en la propiedad de la empresa. Esa información no estuvo disponible por parte del siI para efectos de este trabajo y tampoco es pública. Por lo tanto, se analiza la repercusión de las exenciones y deducciones tributarias usando los datos para 1.000 cuantiles del sil y el impacto del tratamiento especial de las utilidades retenidas utilizando los datos de la encuesta CASEN.

En los dos análisis empíricos realizados que se presentan a continuación se asume, al igual que en Metcalf (1999) y Altshuler, Harris y Toder (2010), que la incidencia del impuesto al ingreso de salarios recae en las personas y la del impuesto a los ingresos corporativos recae en las empresas ${ }^{24}$. Es importante mencionar en todo caso que este supuesto sobre la incidencia del

\footnotetext{
24 En forma similar, Altshuler, Harris y Toder (2010) asumen que las tasas de impuesto más altas a las ganancias de capital y dividendos recaen directamente en las personas que declaran este tipo de ingresos en sus formularios de impuestos.
}

impuesto corporativo solo afecta, en la práctica, al grado de progresividad del impuesto. La evidencia para los Estados Unidos de América es que el impuesto es siempre progresivo, incluso cuando su incidencia recae sobre los salarios en vez de recaer sobre el capital (Harris, 2009).

El principio básico de equidad horizontal en la política tributaria consiste simplemente en que dos individuos que reciben los mismos ingresos pagan el mismo monto de impuestos, independientemente de las fuentes de sus ingresos. En forma complementaria, el principio de equidad vertical consiste en que personas con mayores ingresos paguen en promedio mayores tributos. Es así como un impuesto es progresivo si la tasa promedio de impuestos pagada se incrementa al aumentar el ingreso.

Uno de los índices más utilizados en la literatura para cuantificar el grado de progresividad de un impuesto es el índice de Suits (Suits, 1977), que mide la progresividad a partir de una curva de Lorenz para ingreso y recaudación tributaria como la que se observa en el gráfico 2.

Si se define como K el área bajo la línea de proporcionalidad y como L el área bajo la curva de Lorenz, el índice de Suits se define como:

GRÁFICO 2

\section{Índice de Suits}

Curva de Lorenz

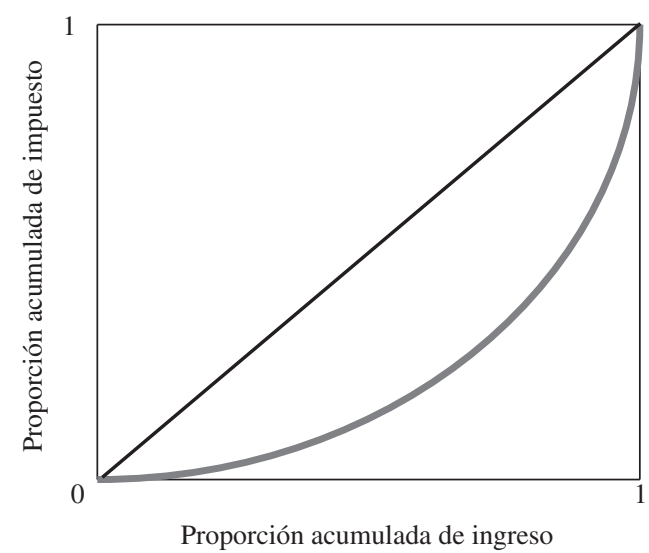

Fuente: elaboración propia sobre la base de datos administrativos del Servicio de Impuestos Internos (SII). 


$$
S=1-\frac{L}{K}=1-\frac{1}{5000} f_{0}^{100} T(Y) d Y
$$

El índice de Suits toma valores entre -1 y 1 . De esta forma, si el impuesto es proporcional: $\mathrm{S}=0$; si el impuesto es progresivo: $\mathrm{S}>0$; y si el impuesto es regresivo: $\mathrm{S}<0$. El uso del índice de Suits permite analizar cambios en progresividad producto de cambios en regímenes tributarios, y el posterior empleo de una técnica estadística de remuestreo (bootstrapping) posibilita estimar intervalos de confianza para el índice. Así, es posible hacer test de hipótesis respecto del cambio en la progresividad impositiva frente a variaciones tributarias (en la base o las tasas del impuesto).

\section{Simulaciones con datos tributarios}

A continuación se presentan los efectos en la distribución del ingreso al eliminar el incentivo tributario al APV.

Los potenciales efectos distributivos de esta exención dependen de la estructura de tramos de ingreso y tasas marginales del impuesto al ingreso, así como de la distribución de ingreso antes de impuestos. En el gráfico 3 se muestra la tasa media de impuesto según cuantil de ingreso, en la que se puede apreciar la pequeña fracción de contribuyentes que pagan el impuesto personal en
Chile. Al dividir la distribución de ingreso antes de impuestos en mil cuantiles, solo el cuantil 824 y los superiores enfrentan una tasa de impuestos promedio positiva. En otras palabras, el 82,3\% de los individuos está bajo el nivel de exención y, por lo tanto, no paga impuesto al ingreso personal ${ }^{25}$. La tasa de impuestos promedio para toda la población de contribuyentes es de $0,63 \%$, la que aumenta a 3,54\% cuando la población se restringe a quienes pagan impuestos. La tasa promedio máxima es de 37,1\% para el cuantil 1.000.

En los gráficos 4 y 5 se observa la distribución del APV por nivel de ingreso. En el gráfico 4 se aprecia que el APV es cercano a cero en los primeros 800 cuantiles y es positivo en los niveles de ingreso para los cuales la tasa marginal de impuestos es mayor que cero. En ambos gráficos se puede constatar claramente como el uso del APV se incrementa con el nivel de ingreso, tal como se esperaría ya que el ahorro tributario es mayor para niveles de ingresos más altos (hasta el tope de 600 UF o 6 UTM por año, dependiendo del régimen seleccionado). En el gráfico 6 se denota además que la fracción de APV con respecto al ingreso antes de impuestos también crece

${ }^{25}$ En este contexto, es curiosa la existencia de siete tasas marginales de impuestos.

GRÁFICO 3

Tasa media de impuesto según cuantil de ingreso

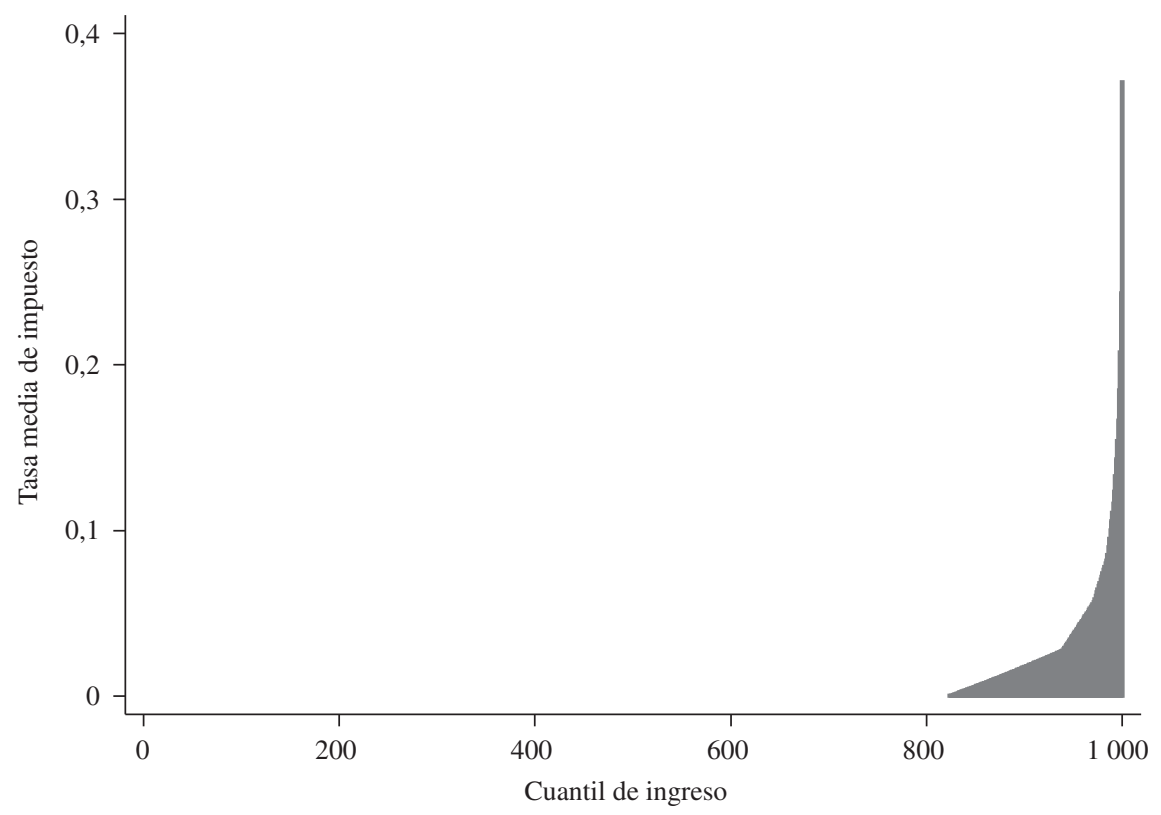

Fuente: elaboración propia sobre la base de datos administrativos del Servicio de Impuestos Internos (SII). 
GRÁFICO 4

\section{Ahorro Previsional Voluntario (APV) según cuantil de ingreso}

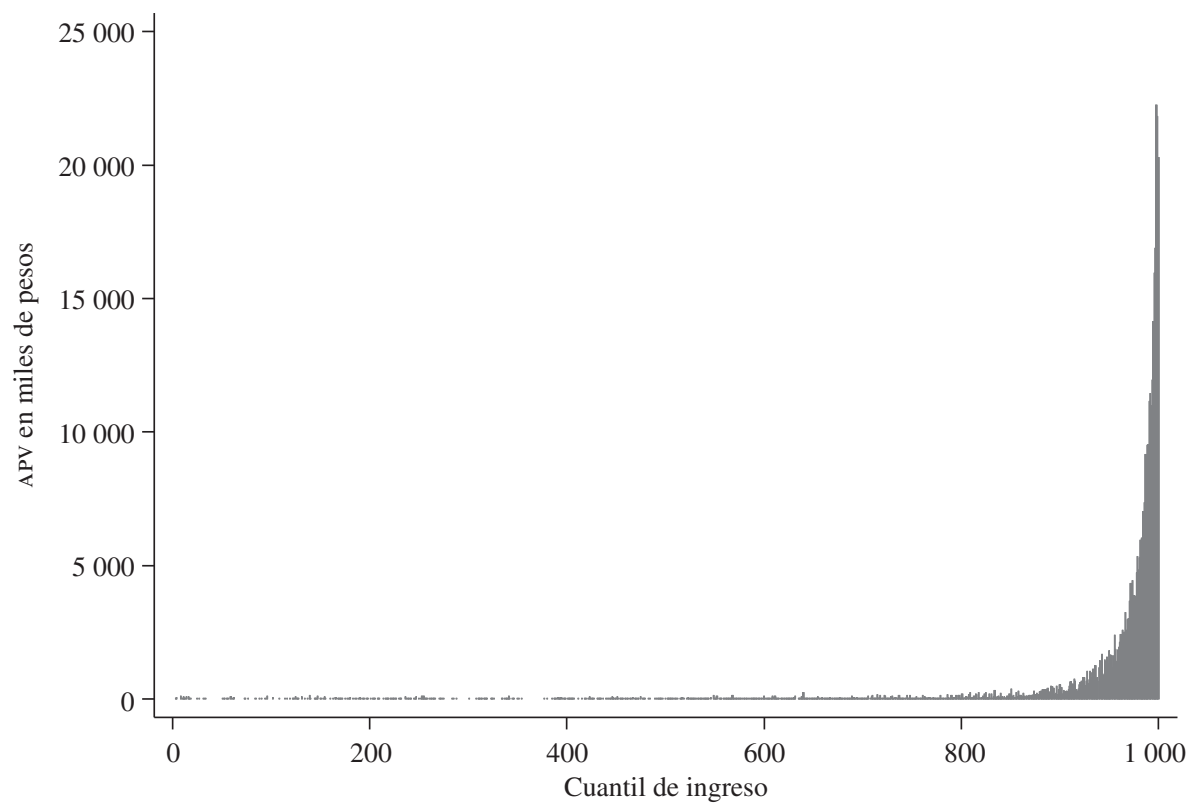

Fuente: elaboración propia sobre la base de datos administrativos del Servicio de Impuestos Internos (SII).

Nota: la variable APV ha sido escalada dividiendo su valor por 100.000 .

GRÁFICO 5

Ahorro Previsional Voluntario (APV) según cuantil de ingreso con tasas de impuesto promedio positivas

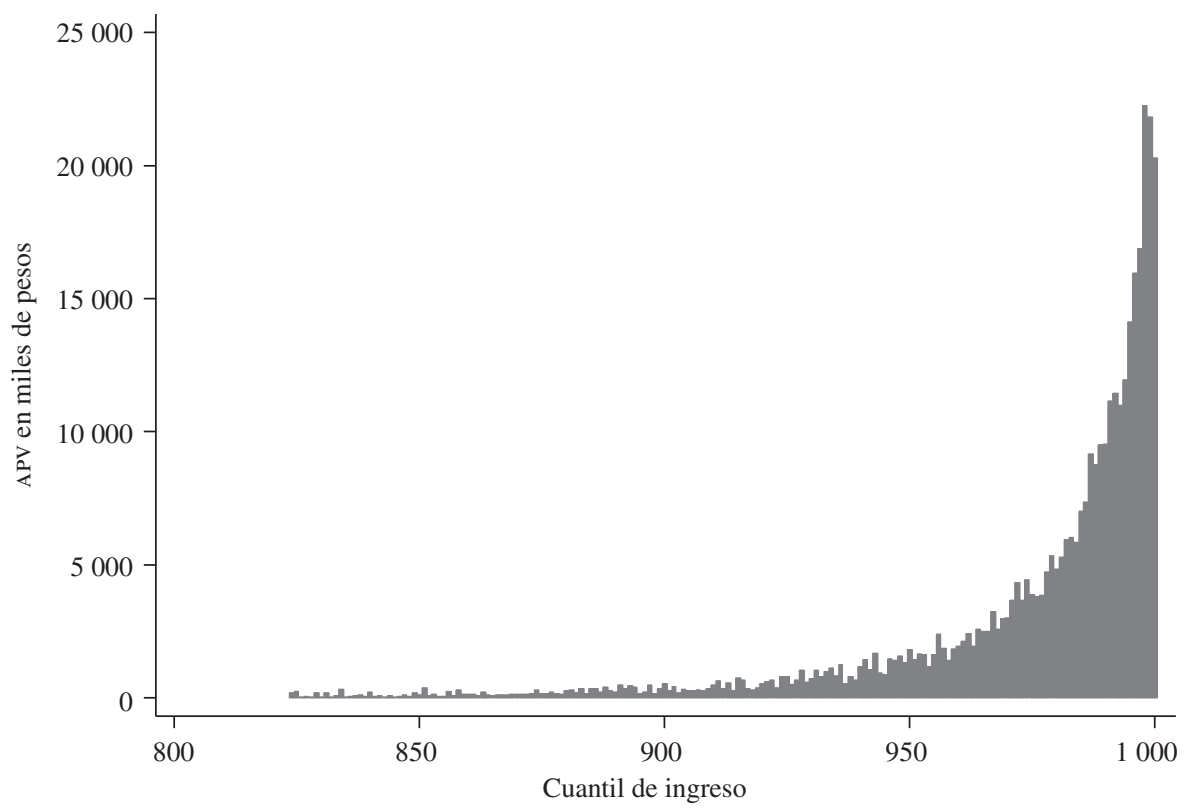

Fuente: elaboración propia sobre la base de datos administrativos del Servicio de Impuestos Internos (sII).

Nota: la variable APV ha sido escalada dividiendo su valor por 100.000. 
GRÁFICO 6

Ahorro Previsional Voluntario (APV) como porcentaje del ingreso para niveles con tasa de impuesto promedio positiva

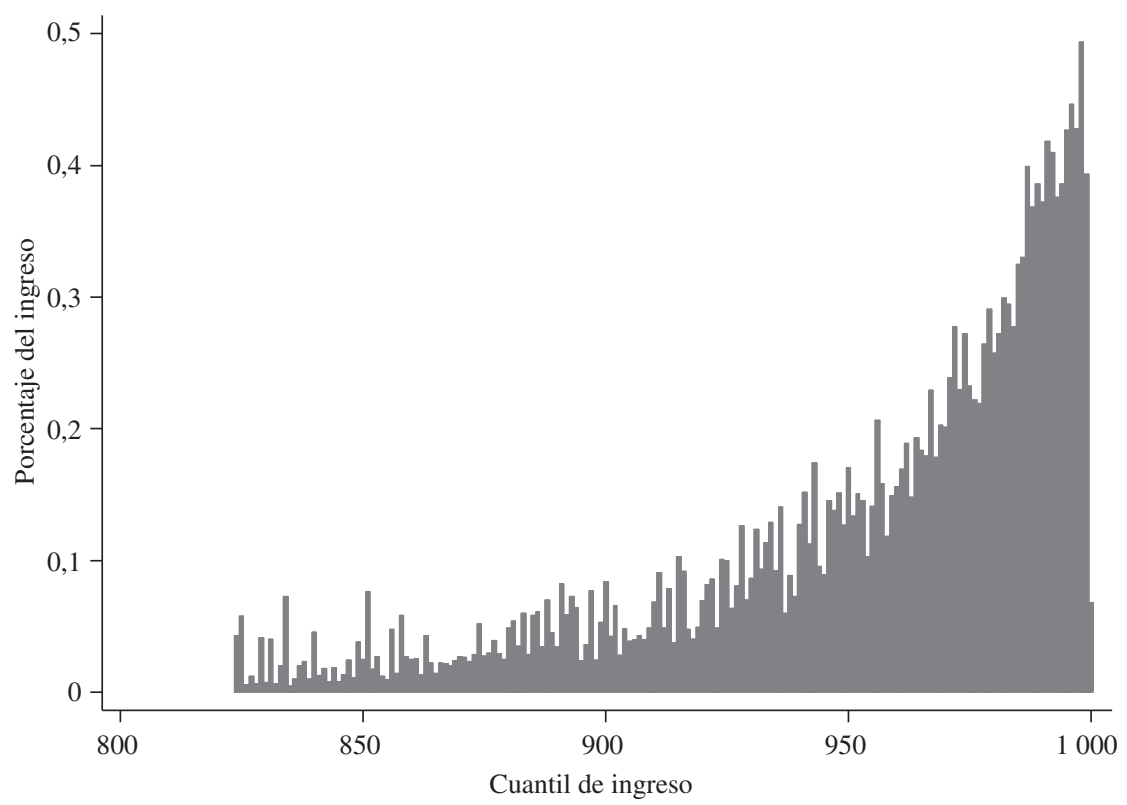

Fuente: elaboración propia sobre la base de datos administrativos del Servicio de Impuestos Internos (sII).

GRÁFICO 7

\section{Exención tributaria del Ahorro Previsional Voluntario (APV) según cuantil de ingreso con tasas de impuesto promedio positivas}

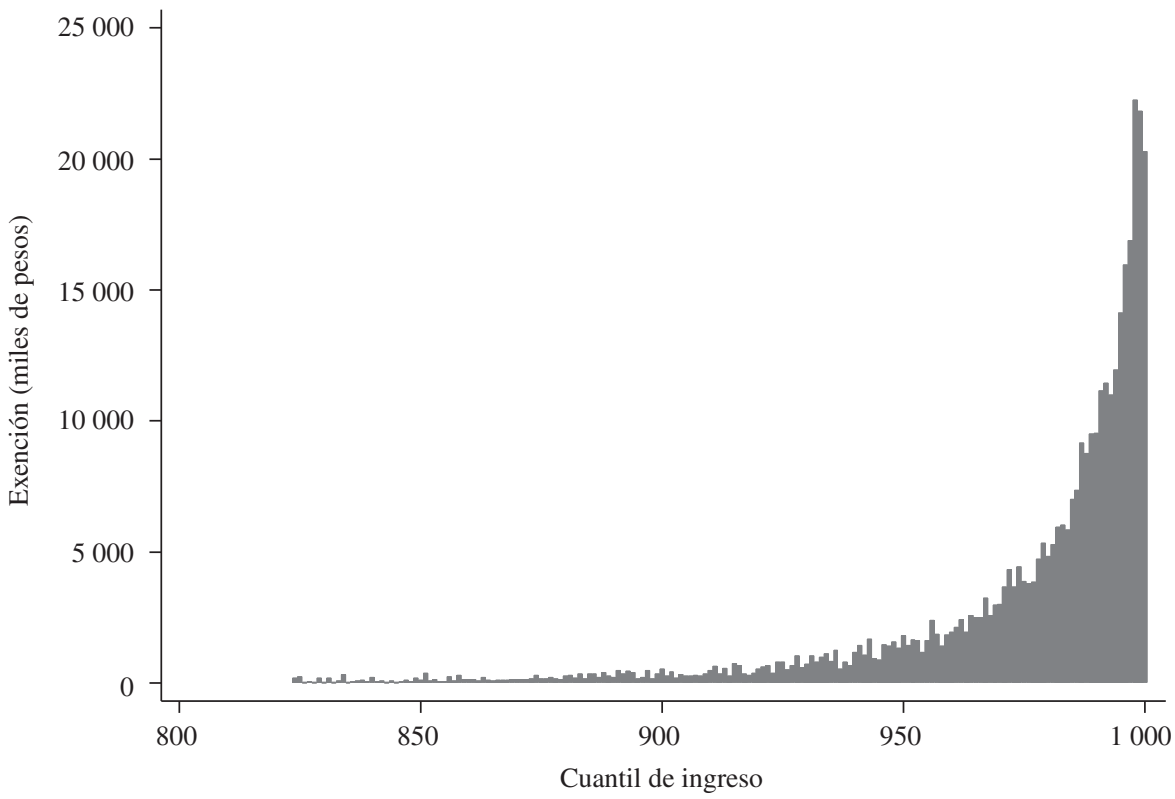

Fuente: elaboración propia sobre la base de datos administrativos del Servicio de Impuestos Internos (SII).

Nota: la variable exención ha sido escalada dividiendo su valor por 100.000. 


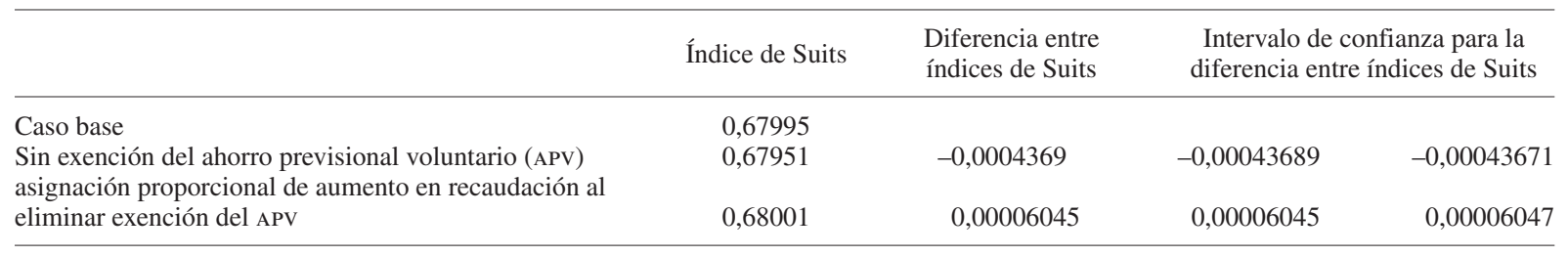

Fuente: elaboración propia sobre la base de datos administrativos del Servicio de Impuestos Internos (sII).

con el nivel de ingresos. En este caso es posible observar con mayor claridad el efecto que tiene el tope de APV, puesto que una vez que se alcanza el tope y el nivel de ingreso es mayor, la fracción de APV cae. No obstante, es importante destacar que la fracción promedio es de apenas un $0,3 \%$.

Dada la evidencia respecto del uso del APV por nivel de ingreso, la eliminación del beneficio tributario debería acrecentar la progresividad del impuesto al ingreso personal. Sin embargo, como la fracción del APV es baja con relación al ingreso antes de impuestos y la gran mayoría de los contribuyentes está exento de pago, su efecto distributivo es limitado. Lo anterior se puede apreciar en el gráfico 7, donde se ilustra el nivel de exención tributaria producto del APV según cuantiles de ingreso que presentan tasas de impuesto promedio positivas.

En el cuadro 4 se muestra el índice de Suits para el impuesto personal al ingreso con y sin el beneficio tributario para el APV. Dicho índice disminuye de 0,67995 a 0,67951, un cambio de magnitud pequeño y en la dirección opuesta a lo esperado, es decir, hacia una menor en lugar de una mayor progresividad. El cambio en el índice sería estadísticamente significativo. Tal como se aprecia en el cuadro 4, el valor cero no está contenido en el intervalo de confianza estimado. En términos de relevancia económica, aunque no estadística, la eliminación del beneficio tributario para el APV no tendría repercusiones distributivas relevantes para efectos de cambiar el potencial papel redistributivo del impuesto al ingreso personal.

Una explicación potencial para la disminución de la progresividad del impuesto al ingreso personal que se produce al eliminar la exención del APV, es el papel que juega el tope máximo del beneficio tributario. Para los individuos de ingresos más altos que realizan APV hasta el tope máximo, este tope representa una fracción pequeña de su ingreso tributable, por lo que al eliminar el beneficio su tasa de impuesto promedio apenas aumenta. Por el contrario, para los individuos de menores ingresos (y con tasas marginales positivas más bajas), el tope del beneficio del APV representa una fracción mayor de su ingreso tributable y, por lo tanto, cuando se elimina el beneficio su tasa media de impuestos se incrementa significativamente. De hecho, el aumento de la tasa media de impuestos en los primeros 10 cuantiles de personas con tasa marginal positiva es de 1,09 puntos porcentuales ${ }^{26}$, mientras que para los 10 cuantiles de más altos ingresos es de 0,34 puntos porcentuales ${ }^{27}$.

Por otra parte, se simuló una situación en que el incremento de la recaudación producido por la eliminación de la exención del APV se distribuyera proporcionalmente en la población. En este caso, el índice de Suits crece levemente de 0,67995 a 0,68001. Esto indicaría un aumento en la progresividad del impuesto al ingreso personal. La diferencia entre ambos índices resulta ser estadísticamente significativa, ya que el intervalo de confianza estimado no contiene el valor cero (véase el cuadro 4). No obstante, en términos económicos, el cambio en el índice no sería relevante en cuanto al efecto distributivo.

El índice de Suits es una aplicación del coeficiente de Gini para medir progresividad tributaria. Por ello, constituye una medida de la progresividad promedio sobre todo el rango de ingreso. Esto se debe tener presente al interpretar el índice, porque hay sistemas tributarios que pueden ser progresivos en algún rango de ingresos y regresivos en otro. En ese sentido, con el índice de Suits no se pueden capturar detalles más sutiles que requieren información sobre momentos de orden mayor de la distribución del pago de impuestos (varianza y curtosis, por ejemplo).

En el caso de Chile, los cambios en la progresividad del impuesto, al eliminar exenciones y deducciones o cambiar las tasas marginales positivas de impuesto, solo

\footnotetext{
26 La tasa de impuesto promedio para dichos 10 cuantiles aumenta de $0,108 \%$ a $0,110 \%$ al eliminar la exención tributaria del APV.

${ }^{27} \mathrm{La}$ tasa de impuesto promedio para dichos 10 cuantiles se incrementa de $18,441 \%$ a $18,504 \%$.
} 
pueden ocurrir en el rango de ingreso de la pequeña fracción de contribuyentes que pagan impuesto a los ingresos personales. La única forma de afectar a una mayor cantidad de contribuyentes con cambios tributarios es reducir el tope de ingresos por el cual las personas están exentas del impuesto personal. Dado que el índice de Suits pondera implícitamente en mayor forma los impuestos pagados por las personas que se hallan en torno de la media de la distribución y que en Chile las personas que están cerca de la media y la mediana no pagan impuestos, es esperable que cambios tributarios que aumenten los impuestos pagados solo por las personas de más altos ingresos — que están en la cola derecha de la distribución - no tengan efectos importantes en el índice. Es posible, entonces, que el índice de Suits —si bien es el más usado en la literatura económica y en los análsis de política tributaria (Oficina de Presupuesto del Congreso, 1988) — no sea el más apropiado para evaluar la progresividad tributaria de una estructura de impuesto al ingreso como la chilena. No está claro, sin embargo, cuál sería el indicador más apropiado de utilizar, ya que no hay otros que hayan demostrado ser superiores al índice de Suits ${ }^{28}$.

\section{Simulaciones con datos de la encuesta CASEN}

Sobre la base de los datos de la encuesta CASEN de 2003, que contiene información acerca de todos los ingresos de los individuos separados por fuente (laborales, arriendos, intereses, ganancias de capital, dividendos, retiros de empresas, ingresos de capital), en este trabajo se simula un cambio en la base tributaria para dividendos y retiros desde utilidades retiradas hasta utilidades devengadas. Este cambio en la base tributaria mantiene la integración del impuesto corporativo con el impuesto al ingreso personal, por lo que se considera un crédito contra el impuesto al ingreso de las personas por el impuesto corporativo pagado por las utilidades devengadas. De esta forma, la tasa final de impuestos que pagan los ingresos es la tasa de impuesto a las personas que paga el socio de la empresa.

En los datos de la encuesta no se observa qué fracción de los dividendos es distribuida y cuál se mantiene como utilidades retenidas. Por ello, para efectos de la

${ }^{28}$ Seetharaman e Iyer (1995) critican los sietes índices de progresividad tributaria que más se usan, incluido el índice de Suits. De igual forma, Kiefer (1984) identifica las inconsistencias de varios índices de progresividad que han sido propuestos. Finalmente, Greene y Balkan (1987) comparan varios de los índices utilizados en la literatura académica. simulación se asume que el total de las utilidades retenidas estimadas por Jorrat (2009) es proporcional a los dividendos reportados por cada individuo en la encuesta CASEN. De esta forma, se imputa un monto de utilidades retenidas a cada individuo en proporción a sus dividen$\operatorname{dos}^{29}$. Luego, se calcula su ingreso antes de impuestos y los impuestos que debiera pagar de acuerdo con las dos diferentes bases tributarias (utilidades distribuidas y utilidades devengadas) ${ }^{30}$.

En el cuadro 5 aparece la tasa de impuestos promedio para cada percentil de ingresos antes y después de esta reforma tributaria en la base del impuesto. Tal como puede verse en dicho cuadro, hay dos efectos significativos. El primero es que ahora muchos contribuyentes bajo el percentil 86 enfrentan una tasa de impuestos positiva, mientras que antes de la reforma no pagaban impuestos. Esto deja ver la magnitud de la inequidad horizontal existente con la base tributaria actual, ya que muchos contribuyentes que debieran pagar impuestos de acuerdo con su nivel de ingresos logran postergarlo porque su principal fuentes de ingresos son las utilidades de las empresas de las que son propietarios. Si esos contribuyentes tuvieran los mismos niveles de ingresos, pero la fuente fuera únicamente de ingresos laborales, pagarían impuestos de acuerdo con la base tributaria actual, dado que esta base no cambiaría al agregar las utilidades de las empresas. El segundo efecto de esta reforma es que los contribuyentes que actualmente pagan impuestos

\footnotetext{
${ }^{29}$ Se calculan los intereses y dividendos anuales de los individuos y se estima su participación en los intereses y dividendos totales de la población. Luego, se asignan los 450 mil 625 millones de pesos de gasto tributario estimado por la Subdirección de Estudios del Servicio de Impuestos Internos para el año 2003 (Informe de Gasto Tributario de Diciembre de 2004) a cada individuo, según su participación en los intereses y dividendos totales de la población.

30 No se utiliza el índice de Suits para estudiar el efecto en la progresividad de reformas tributarias con datos de la encuesta CASEN por dos motivos. Primero, la progresividad del impuesto a la renta en Chile depende críticamente del aumento en la tasa media de quienes pagan este impuesto a medida que se incrementa el ingreso. Sin embargo, como solo un $17,3 \%$ de los receptores de ingreso pagan impuestos a la renta, la progresividad del impuesto depende exclusivamente de lo que sucede en la cola de la distribución. En segundo lugar, la encuesta CASEN cuyo objetivo primordial es el estudio de la pobreza, tiene proporcionalmente menos observaciones en la cola superior de la distribución que los datos poblacionales del siI. Estas dificultades no impiden calcular y reportar las tasas medias del impuesto a la renta como una aproximación correcta para cuantificar los efectos de una reforma tributaria en la distribución del ingreso, pero sí impiden medir correctamente la progresividad total del impuesto a la renta medida por medio del índice de Suits. Estas dificultades se traducen en que al calcular el índice de Suits con los datos de la encuesta CASEN, este es del orden de 0,23 , lo que no se condice con los índices de Suits calculados a partir de los datos del siI, que incluyen al total de la población de contribuyentes.
} 
CUADRO 5

Tasa de impuesto promedio según centil de ingreso, antes y después de reforma tributaria

\begin{tabular}{|c|c|c|}
\hline Centil & Tasa de impuesto promedio (utilidades distribuidas) & Tasa de impuesto promedio (utilidades devengadas) \\
\hline 1 & 0,001 & 0,000 \\
\hline 2 & 0,005 & 0,000 \\
\hline 3 & 0,009 & 0,000 \\
\hline 4 & 0,000 & 0,000 \\
\hline 5 & 0,002 & 0,000 \\
\hline 6 & 0,001 & 0,000 \\
\hline 7 & 0,001 & 0,000 \\
\hline 8 & 0,000 & 0,000 \\
\hline 9 & 0,000 & 0,000 \\
\hline 10 & 0,000 & 0,000 \\
\hline 11 & 0,003 & 0,000 \\
\hline 12 & 0,001 & 0,000 \\
\hline 13 & 0,000 & 0,000 \\
\hline 14 & 0,000 & 0,000 \\
\hline 15 & 0,000 & 0,000 \\
\hline 16 & 0,000 & 0,000 \\
\hline 17 & 0,000 & 0,000 \\
\hline 18 & 0,000 & 0,000 \\
\hline 19 & 0,001 & 0,000 \\
\hline 20 & 0,004 & 0,000 \\
\hline 21 & 0,000 & 0,000 \\
\hline 22 & 0,000 & 0,000 \\
\hline 23 & 0,000 & 0,000 \\
\hline 24 & 0,000 & 0,000 \\
\hline 25 & 0,000 & 0,000 \\
\hline 26 & 0,000 & 0,000 \\
\hline 27 & 0,001 & 0,000 \\
\hline 28 & 0,000 & 0,000 \\
\hline 29 & 0,000 & 0,000 \\
\hline 30 & 0,000 & 0,000 \\
\hline 31 & 0,001 & 0,000 \\
\hline 32 & 0,003 & 0,000 \\
\hline 33 & 0,002 & 0,000 \\
\hline 34 & 0,001 & 0,000 \\
\hline 35 & 0,000 & 0,000 \\
\hline 36 & 0,001 & 0,000 \\
\hline 37 & 0,000 & 0,000 \\
\hline 38 & 0,002 & 0,000 \\
\hline 39 & 0,001 & 0,000 \\
\hline 40 & 0,001 & 0,000 \\
\hline 41 & 0,000 & 0,000 \\
\hline 42 & 0,000 & 0,000 \\
\hline 43 & 0,001 & 0,000 \\
\hline 44 & 0,000 & 0,000 \\
\hline 45 & 0,000 & 0,000 \\
\hline 46 & 0,001 & 0,000 \\
\hline 47 & 0,007 & 0,000 \\
\hline 48 & 0,002 & 0,000 \\
\hline 49 & 0,002 & 0,000 \\
\hline 50 & 0,001 & 0,000 \\
\hline 51 & 0,001 & 0,000 \\
\hline 52 & 0,002 & 0,000 \\
\hline 53 & 0,001 & 0,000 \\
\hline
\end{tabular}

(Continúa en página siguiente) 
(Conclusión)

\begin{tabular}{|c|c|c|}
\hline Centil & Tasa de impuesto promedio (utilidades distribuidas) & Tasa de impuesto promedio (utilidades devengadas) \\
\hline 54 & 0,001 & 0,000 \\
\hline 55 & 0,000 & 0,000 \\
\hline 56 & 0,002 & 0,000 \\
\hline 57 & 0,001 & 0,000 \\
\hline 58 & 0,002 & 0,000 \\
\hline 59 & 0,002 & 0,000 \\
\hline 60 & 0,001 & 0,000 \\
\hline 61 & 0,003 & 0,000 \\
\hline 62 & 0,001 & 0,000 \\
\hline 63 & 0,000 & 0,000 \\
\hline 64 & 0,002 & 0,000 \\
\hline 65 & 0,001 & 0,000 \\
\hline 66 & 0,002 & 0,000 \\
\hline 67 & 0,000 & 0,000 \\
\hline 68 & 0,001 & 0,000 \\
\hline 69 & 0,001 & 0,000 \\
\hline 70 & 0,006 & 0,000 \\
\hline 71 & 0,001 & 0,000 \\
\hline 72 & 0,002 & 0,000 \\
\hline 73 & 0,001 & 0,000 \\
\hline 74 & 0,003 & 0,000 \\
\hline 75 & 0,004 & 0,000 \\
\hline 76 & 0,001 & 0,000 \\
\hline 77 & 0,002 & 0,000 \\
\hline 78 & 0,001 & 0,000 \\
\hline 79 & 0,001 & 0,000 \\
\hline 80 & 0,002 & 0,000 \\
\hline 81 & 0,004 & 0,000 \\
\hline 82 & 0,005 & 0,000 \\
\hline 83 & 0,003 & 0,000 \\
\hline 84 & 0,004 & 0,000 \\
\hline 85 & 0,007 & 0,000 \\
\hline 86 & 0,002 & 0,001 \\
\hline 87 & 0,007 & 0,003 \\
\hline 88 & 0,010 & 0,006 \\
\hline 89 & 0,013 & 0,008 \\
\hline 90 & 0,018 & 0,011 \\
\hline 91 & 0,018 & 0,014 \\
\hline 92 & 0,027 & 0,016 \\
\hline 93 & 0,028 & 0,018 \\
\hline 94 & 0,036 & 0,022 \\
\hline 95 & 0,034 & 0,024 \\
\hline 96 & 0,039 & 0,028 \\
\hline 97 & 0,048 & 0,037 \\
\hline 98 & 0,068 & 0,052 \\
\hline 99 & 0,098 & 0,078 \\
\hline 100 & 0,211 & 0,188 \\
\hline
\end{tabular}

Fuente: elaboración propia sobre la base de la encuesta de Caracterización Socioeconómica Nacional (CASEN), 2003.

al ingreso personal enfrentarían una tasa impositiva marginal mucho más alta al pasar a tramos superiores de ingreso tributable. Sin duda, un cambio tributario como el simulado generaría respuesta de comportamiento de los contribuyentes, quienes procurarían disminuir su carga tributaria (trabajarían menos, por ejemplo). Por eso, el cambio de progresividad producido por esta reforma tributaria debe considerarse como el máximo cambio esperado al modificar la base del impuesto de utilidades retiradas a utilidades devengadas. 


\section{V}

\section{Conclusiones}

En este trabajo se ha estudiado el efecto distributivo que tienen las principales exenciones y deducciones en el impuesto al ingreso en Chile. Para ello se utilizaron, además de la encuesta CASEN, que es una base de datos conocida y bastante empleada en diversos estudios, datos exclusivos de impuestos generados por el sII.

Los datos de impuestos muestran que el $82 \%$ de las personas se encuentran exentas del pago de impuesto al ingreso personal dado su nivel de ingresos y la estructura de tramos de ingresos y tasas marginales del impuesto. En este contexto, los resultados del análisis empírico permiten ver que la exención al APV no tiene un efecto económicamente significativo en la progresividad del impuesto al ingreso. Si bien las personas de ingresos más altos son las que se acogen a estas exenciones y deducciones tributarias y además su uso aumenta con el nivel de ingreso, la magnitud relativamente pequeña de los beneficios tributarios con respecto al ingreso y el hecho de que pocas personas enfrenten una tasa de impuesto positiva, hacen que la eliminación de estos beneficios tenga muy escasa incidencia en mejorar la progresividad del impuesto al ingreso.

Un resultado distinto emerge al considerar una reforma tributaria en que se elimine el beneficio tributario mayor, en términos de gasto tributario, consistente en imponer por las utilidades de las empresas sobre la base de los retiros efectuados por sus dueños. Sobre la base de los datos de la encuesta CASEN y asumiendo un escenario conservador respecto de la distribución de utilidades, se simuló un cambio del impuesto corporativo que considera el pago de impuestos en base devengada en vez de en base a retiros, pero que mantiene la integración con el impuesto a las personas. Los resultados de este análisis empírico muestran que una reforma tributaria de este tipo tiene efectos importantes en el aumento de la progresividad del impuesto al ingreso personal y disminuye la desigualdad del ingreso después de impuestos.

Los resultados de este trabajo entregan un marco de análisis relevante y útil para entender el sistema de impuesto a la renta en Chile y su potencial como herramienta redistributiva. En primer lugar, el hecho de que solo el $8 \%$ de los contribuyentes estén afectos a una tasa de impuesto positiva conduce a que cualquier exención tributaria beneficie a las personas de más altos ingresos. Esto no solo limita el impuesto al ingreso como herramienta para disminuir la gran desigualdad de ingresos existente en el país, sino que además debiera encender el debate público y parlamentario sobre la inconveniencia de introducir exenciones en el impuesto al ingreso. Cualquier exención no solo genera ineficiencias y abre espacios de evasión, sino que además favorece siempre al $10 \%$ más rico de la población. En segundo lugar, dada la pequeña fracción de personas que pagan impuestos, únicamente cambios que afecten a beneficios tributarios de gran magnitud pueden tener el potencial de lograr que el impuesto sea más progresivo. Eliminar el beneficio de que actualmente disponen las utilidades retenidas de las empresas es uno de esos cambios posibles. En tercer lugar, el hecho de que la eliminación de exenciones tributarias no repercuta fuertemente en la progresividad del impuesto al ingreso personal no implica que este no pueda ser utilizado como herramienta para redistribuir el ingreso. La conclusión es que se requieren cambios mayores en la estructura tributaria actual para que sea una herramienta efectiva. Uno de los aspectos a discutir acerca de esta estructura es precisamente el actual nivel de ingreso exento, que se traduce en que casi el $90 \%$ de la población no tenga que pagar impuestos al ingreso.

Este trabajo ofrece varias extensiones posibles y relevantes, que lamentablemente dependen del acceso a datos proporcionados por el sistema de administración tributaria. En particular, podría analizarse con más detalle cada una de las otras exenciones, créditos y deducciones existentes tanto en el impuesto al ingreso personal como en el impuesto corporativo, ya sea para describir sus efectos distributivos como para estimar su repercusión en el comportamiento de los individuos. 
Porcentaje de aumento del ingreso imponible e impuesto pagado después de eliminar exención del APV, según centil (Centiles que pagan impuesto)

\begin{tabular}{|c|c|c|}
\hline Centil & Porcentaje de aumento del ingreso & Porcentaje de aumento del impuesto \\
\hline 824 & 0,04 & 21,76 \\
\hline 825 & 0,06 & 9,16 \\
\hline 826 & 0,01 & 0,56 \\
\hline 827 & 0,01 & 0,83 \\
\hline 828 & 0,01 & 0,33 \\
\hline 829 & 0,04 & 1,73 \\
\hline 830 & 0,01 & 0,25 \\
\hline 831 & 0,04 & 1,22 \\
\hline 832 & 0,01 & 0,17 \\
\hline 833 & 0,02 & 0,49 \\
\hline 834 & 0,07 & 1,58 \\
\hline 835 & 0,00 & 0,10 \\
\hline 836 & 0,01 & 0,18 \\
\hline 837 & 0,02 & 0,34 \\
\hline 838 & 0,02 & 0,36 \\
\hline 839 & 0,01 & 0,15 \\
\hline 840 & 0,05 & 0,62 \\
\hline 841 & 0,01 & 0,16 \\
\hline 842 & 0,02 & 0,22 \\
\hline 843 & 0,01 & 0,09 \\
\hline 844 & 0,02 & 0,20 \\
\hline 845 & 0,01 & 0,08 \\
\hline 846 & 0,01 & 0,13 \\
\hline 847 & 0,02 & 0,23 \\
\hline 848 & 0,01 & 0,10 \\
\hline 849 & 0,04 & 0,34 \\
\hline 850 & 0,02 & 0,21 \\
\hline 851 & 0,08 & 0,62 \\
\hline 852 & 0,02 & 0,14 \\
\hline 853 & 0,03 & 0,21 \\
\hline 854 & 0,01 & 0,09 \\
\hline 855 & 0,01 & 0,07 \\
\hline 856 & 0,05 & 0,33 \\
\hline 857 & 0,01 & 0,09 \\
\hline 858 & 0,06 & 0,38 \\
\hline 859 & 0,03 & 0,17 \\
\hline 860 & 0,02 & 0,15 \\
\hline 861 & 0,03 & 0,15 \\
\hline 862 & 0,01 & 0,08 \\
\hline 863 & 0,04 & 0,24 \\
\hline 864 & 0,02 & 0,12 \\
\hline 865 & 0,01 & 0,08 \\
\hline 866 & 0,02 & 0,12 \\
\hline 867 & 0,02 & 0,11 \\
\hline 868 & 0,02 & 0,10 \\
\hline 869 & 0,02 & 0,12 \\
\hline 870 & 0,03 & 0,13 \\
\hline 871 & 0,03 & 0,12 \\
\hline 872 & 0,02 & 0,11 \\
\hline 873 & 0,03 & 0,13 \\
\hline 874 & 0,05 & 0,23 \\
\hline 875 & 0,03 & 0,12 \\
\hline 876 & 0,03 & 0,13 \\
\hline 877 & 0,04 & 0,16 \\
\hline 878 & 0,03 & 0,12 \\
\hline 879 & 0,02 & 0,10 \\
\hline 880 & 0,05 & 0,19 \\
\hline 881 & 0,05 & 0,21 \\
\hline
\end{tabular}


(Continuación)

\begin{tabular}{|c|c|c|}
\hline Centil & Porcentaje de aumento del ingreso & Porcentaje de aumento del impuesto \\
\hline 882 & 0,04 & 0,13 \\
\hline 883 & 0,06 & 0,22 \\
\hline 885 & 0,06 & 0,21 \\
\hline 886 & 0,06 & 0,21 \\
\hline 887 & 0,03 & 0,12 \\
\hline 888 & 0,07 & 0,24 \\
\hline 889 & 0,04 & 0,15 \\
\hline 890 & 0,03 & 0,11 \\
\hline 891 & 0,08 & 0,27 \\
\hline 892 & 0,06 & 0,19 \\
\hline 893 & 0,07 & 0,23 \\
\hline 894 & 0,06 & 0,20 \\
\hline 895 & 0,02 & 0,07 \\
\hline 896 & 0,04 & 0,11 \\
\hline 898 & 0,02 & 0,07 \\
\hline 899 & 0,05 & 0,15 \\
\hline 900 & 0,08 & 0,24 \\
\hline 901 & 0,04 & 0,12 \\
\hline 902 & 0,07 & 0,18 \\
\hline 903 & 0,03 & 0,08 \\
\hline 904 & 0,05 & 0,13 \\
\hline 905 & 0,04 & 0,10 \\
\hline 906 & 0,04 & 0,10 \\
\hline 907 & 0,04 & 0,11 \\
\hline 908 & 0,04 & 0,10 \\
\hline 909 & 0,05 & 0,12 \\
\hline 910 & 0,07 & 0,17 \\
\hline 911 & 0,09 & 0,22 \\
\hline 912 & 0,05 & 0,12 \\
\hline 913 & 0,08 & 0,19 \\
\hline 916 & 0,09 & 0,21 \\
\hline 917 & 0,05 & 0,11 \\
\hline 918 & 0,04 & 0,09 \\
\hline 919 & 0,05 & 0,11 \\
\hline 920 & 0,07 & 0,15 \\
\hline 921 & 0,08 & 0,18 \\
\hline 922 & 0,09 & 0,19 \\
\hline 923 & 0,05 & 0,10 \\
\hline 924 & 0,10 & 0,21 \\
\hline 925 & 0,10 & 0,21 \\
\hline 926 & 0,06 & 0,13 \\
\hline 927 & 0,08 & 0,17 \\
\hline 928 & 0,13 & 0,26 \\
\hline 929 & 0,07 & 0,14 \\
\hline 930 & 0,09 & 0,17 \\
\hline 931 & 0,12 & 0,24 \\
\hline 932 & 0,09 & 0,18 \\
\hline 933 & 0,11 & 0,22 \\
\hline 934 & 0,13 & 0,25 \\
\hline 935 & 0,09 & 0,17 \\
\hline 936 & 0,14 & 0,26 \\
\hline 937 & 0,06 & 0,11 \\
\hline 938 & 0,09 & 0,16 \\
\hline 939 & 0,07 & 0,23 \\
\hline 940 & 0,13 & 0,45 \\
\hline 941 & 0,15 & 0,52 \\
\hline 942 & 0,11 & 0,37 \\
\hline 943 & 0,17 & 0,56 \\
\hline
\end{tabular}


(Conclusión)

\begin{tabular}{|c|c|c|}
\hline Centil & Porcentaje de aumento del ingreso & Porcentaje de aumento del impuesto \\
\hline 944 & 0,10 & 0,30 \\
\hline 945 & 0,09 & 0,27 \\
\hline 946 & 0,15 & 0,43 \\
\hline 947 & 0,14 & 0,40 \\
\hline 948 & 0,15 & 0,43 \\
\hline 949 & 0,13 & 0,35 \\
\hline 950 & 0,17 & 0,46 \\
\hline 951 & 0,13 & 0,35 \\
\hline 952 & 0,15 & 0,39 \\
\hline 953 & 0,15 & 0,36 \\
\hline 954 & 0,10 & 0,25 \\
\hline 955 & 0,14 & 0,34 \\
\hline 956 & 0,21 & 0,48 \\
\hline 957 & 0,16 & 0,36 \\
\hline 958 & 0,12 & 0,27 \\
\hline 959 & 0,15 & 0,33 \\
\hline 960 & 0,16 & 0,34 \\
\hline 961 & 0,17 & 0,36 \\
\hline 962 & 0,19 & 0,39 \\
\hline 963 & 0,15 & 0,30 \\
\hline 964 & 0,19 & 0,39 \\
\hline 965 & 0,18 & 0,36 \\
\hline 966 & 0,18 & 0,35 \\
\hline 967 & 0,23 & 0,43 \\
\hline 968 & 0,18 & 0,33 \\
\hline 969 & 0,20 & 0,37 \\
\hline 970 & 0,20 & 0,36 \\
\hline 971 & 0,24 & 0,63 \\
\hline 972 & 0,28 & 0,71 \\
\hline 973 & 0,23 & 0,57 \\
\hline 974 & 0,27 & 0,65 \\
\hline 975 & 0,23 & 0,54 \\
\hline 976 & 0,22 & 0,50 \\
\hline 977 & 0,22 & 0,48 \\
\hline 978 & 0,26 & 0,56 \\
\hline 979 & 0,29 & 0,60 \\
\hline 980 & 0,26 & 0,52 \\
\hline 981 & 0,27 & 0,54 \\
\hline 982 & 0,30 & 0,57 \\
\hline 983 & 0,29 & 0,55 \\
\hline 984 & 0,28 & 0,51 \\
\hline 985 & 0,32 & 0,95 \\
\hline 986 & 0,33 & 0,92 \\
\hline 987 & 0,40 & 1,05 \\
\hline 988 & 0,37 & 0,92 \\
\hline 989 & 0,39 & 0,91 \\
\hline 990 & 0,37 & 0,84 \\
\hline 991 & 0,42 & 0,90 \\
\hline 992 & 0,41 & 1,06 \\
\hline 993 & 0,38 & 0,91 \\
\hline 994 & 0,39 & 0,86 \\
\hline 995 & 0,43 & 0,89 \\
\hline 996 & 0,45 & 0,86 \\
\hline 997 & 0,43 & 0,86 \\
\hline 998 & 0,49 & 0,88 \\
\hline 999 & 0,39 & 0,65 \\
\hline 1000 & 0,07 & 0,07 \\
\hline
\end{tabular}

Fuente: elaboración propia sobre la base de datos administrativos del Servicio de Impuestos Internos (sII).

APV: Ahorro Previsional Voluntario. 
CUADRO 7

Participación en el impuesto total pagado por centil antes y

después de eliminar la exención del APV

(Centiles que pagan impuesto)

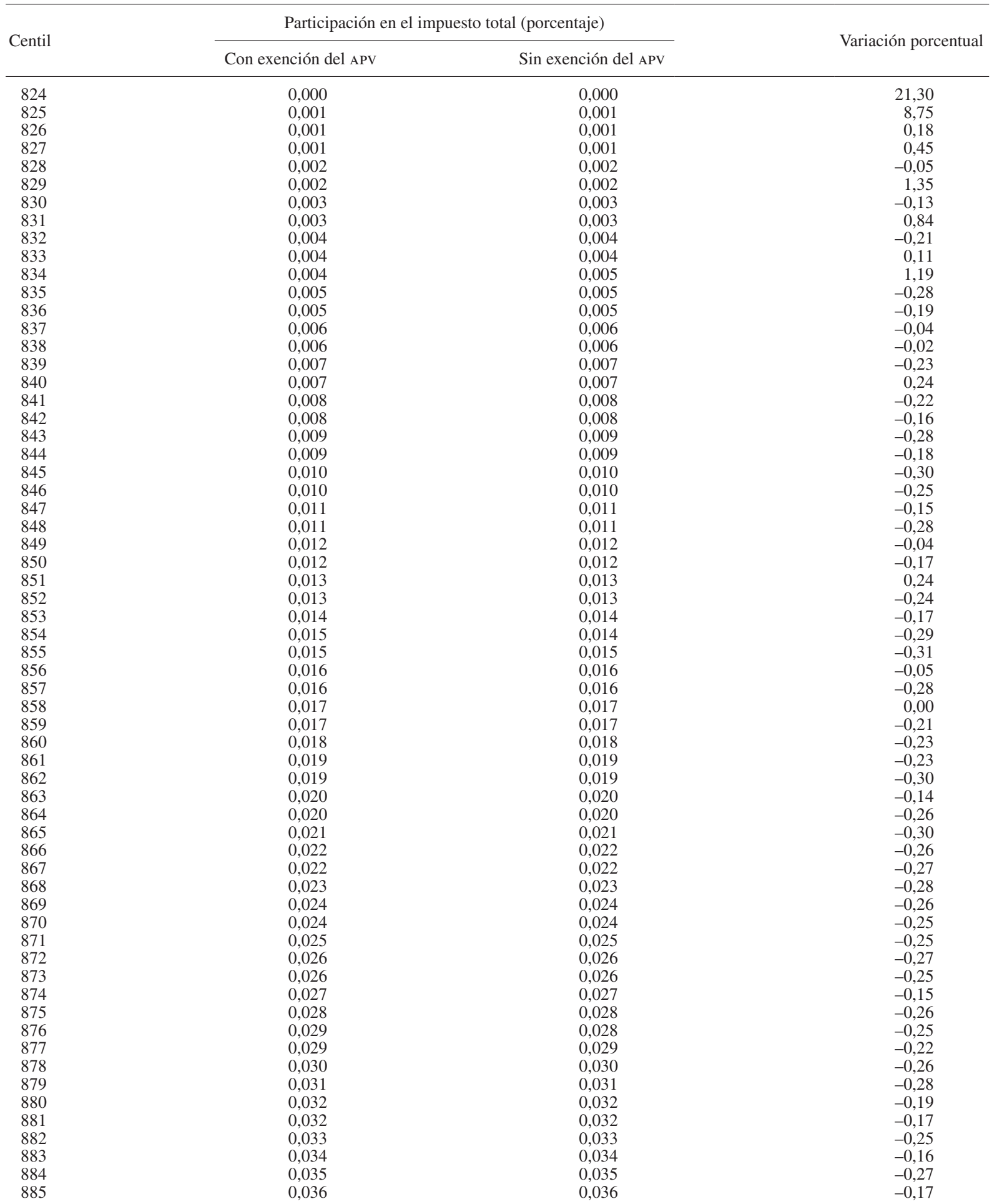

(Continúa en página siguiente) 
(Continuación)

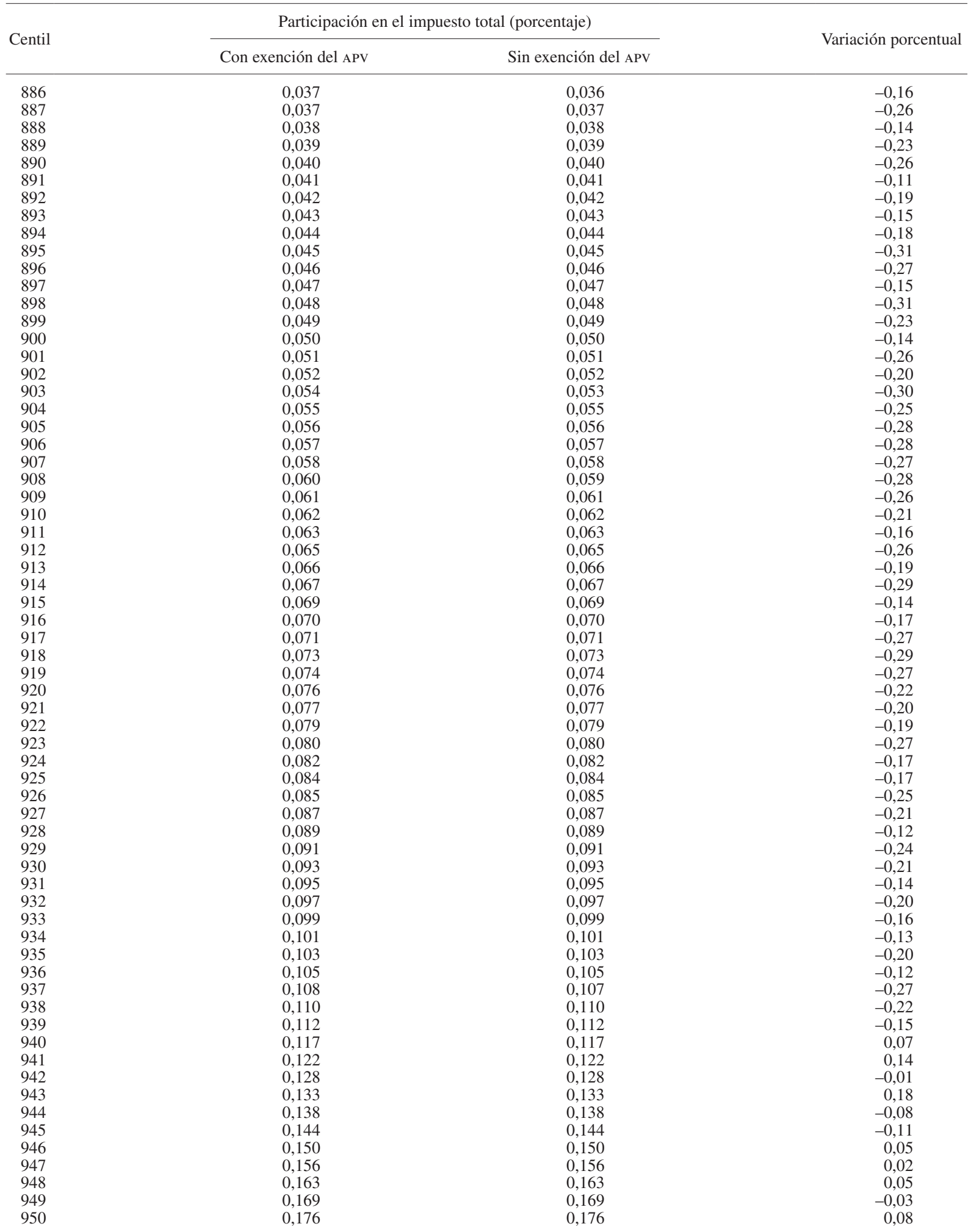


(Conclusión)

\begin{tabular}{|c|c|c|c|}
\hline \multirow{2}{*}{ Centil } & \multicolumn{2}{|c|}{ Participación en el impuesto total (porcentaje) } & \multirow{2}{*}{ Variación porcentual } \\
\hline & Con exención del APV & Sin exención del APV & \\
\hline 951 & 0,183 & 0,183 & $-0,03$ \\
\hline 952 & 0,190 & 0,190 & 0,01 \\
\hline 953 & 0,198 & 0,197 & $-0,02$ \\
\hline 954 & 0,205 & 0,205 & $-0,13$ \\
\hline 955 & 0,213 & 0,213 & $-0,04$ \\
\hline 956 & 0,221 & 0,221 & 0,10 \\
\hline 957 & 0,229 & 0,229 & $-0,02$ \\
\hline 958 & 0,238 & 0,238 & $-0,11$ \\
\hline 959 & 0,247 & 0,247 & $-0,05$ \\
\hline 960 & 0,257 & 0,257 & $-0,04$ \\
\hline 961 & 0,267 & 0,267 & $-0,02$ \\
\hline 962 & 0,277 & 0,277 & 0,01 \\
\hline 963 & 0,287 & 0,287 & $-0,08$ \\
\hline 964 & 0,298 & 0,298 & 0,01 \\
\hline 965 & 0,309 & 0,309 & $-0,02$ \\
\hline 966 & 0,321 & 0,321 & $-0,03$ \\
\hline 967 & 0,333 & 0,333 & 0,05 \\
\hline 968 & 0,346 & 0,345 & $-0,05$ \\
\hline 969 & 0,359 & 0,358 & $-0,01$ \\
\hline 970 & 0,372 & 0,372 & $-0,02$ \\
\hline 971 & 0,387 & 0,388 & 0,25 \\
\hline 972 & 0,409 & 0,410 & 0,33 \\
\hline 973 & 0,432 & 0,433 & 0,19 \\
\hline 974 & 0,456 & 0,458 & 0,27 \\
\hline 975 & 0,481 & 0,482 & 0,16 \\
\hline 976 & 0,507 & 0,507 & 0,12 \\
\hline 977 & 0,534 & 0,535 & 0,10 \\
\hline 978 & 0,563 & 0,564 & 0,18 \\
\hline 979 & 0,593 & 0,594 & 0,22 \\
\hline 980 & 0,624 & 0,625 & 0,14 \\
\hline 981 & 0,658 & 0,660 & 0,16 \\
\hline 982 & 0,694 & 0,695 & 0,19 \\
\hline 983 & 0,731 & 0,733 & 0,17 \\
\hline 984 & 0,770 & 0,771 & 0,13 \\
\hline 985 & 0,822 & 0,826 & 0,57 \\
\hline 986 & 0,895 & 0,900 & 0,53 \\
\hline 987 & 0,973 & 0,980 & 0,67 \\
\hline 988 & 1,062 & 1,068 & 0,54 \\
\hline 989 & 1,161 & 1,167 & 0,53 \\
\hline 990 & 1,269 & 1,275 & 0,46 \\
\hline 991 & 1,388 & 1,395 & 0,52 \\
\hline 992 & 1,535 & 1,546 & 0,68 \\
\hline 993 & 1,735 & 1,744 & 0,52 \\
\hline 994 & 1,978 & 1,988 & 0,48 \\
\hline 995 & 2,280 & 2,291 & 0,50 \\
\hline 996 & 2,659 & 2,672 & 0,48 \\
\hline 997 & 3,257 & 3,272 & 0,48 \\
\hline 998 & 4,182 & 4,202 & 0,50 \\
\hline 999 & 6,034 & 6,050 & 0,27 \\
\hline 1000 & 49,317 & 49,167 & $-0,30$ \\
\hline
\end{tabular}

Fuente: elaboración propia sobre la base de datos administrativos del Servicio de Impuestos Internos (sII). APV: Ahorro Previsional Voluntario.

CUADRO 8

Cambio en la recaudación total al eliminar exenciones

\begin{tabular}{lc}
\hline Recaudación & $\begin{array}{c}\text { Millones de pesos } \\
\text { Caso base }\end{array}$ \\
\hline Sin exención del ahorro previsional voluntario (APV) & 2240000 \\
de situación base & 2250000 \\
\hline
\end{tabular}

Fuente: elaboración propia sobre la base de datos administrativos del Servicio de Impuestos Internos (SII). 
GRÁFICO 8 Tasa de impuesto promedio según centil de ingreso con autorreporte de intereses y dividendos

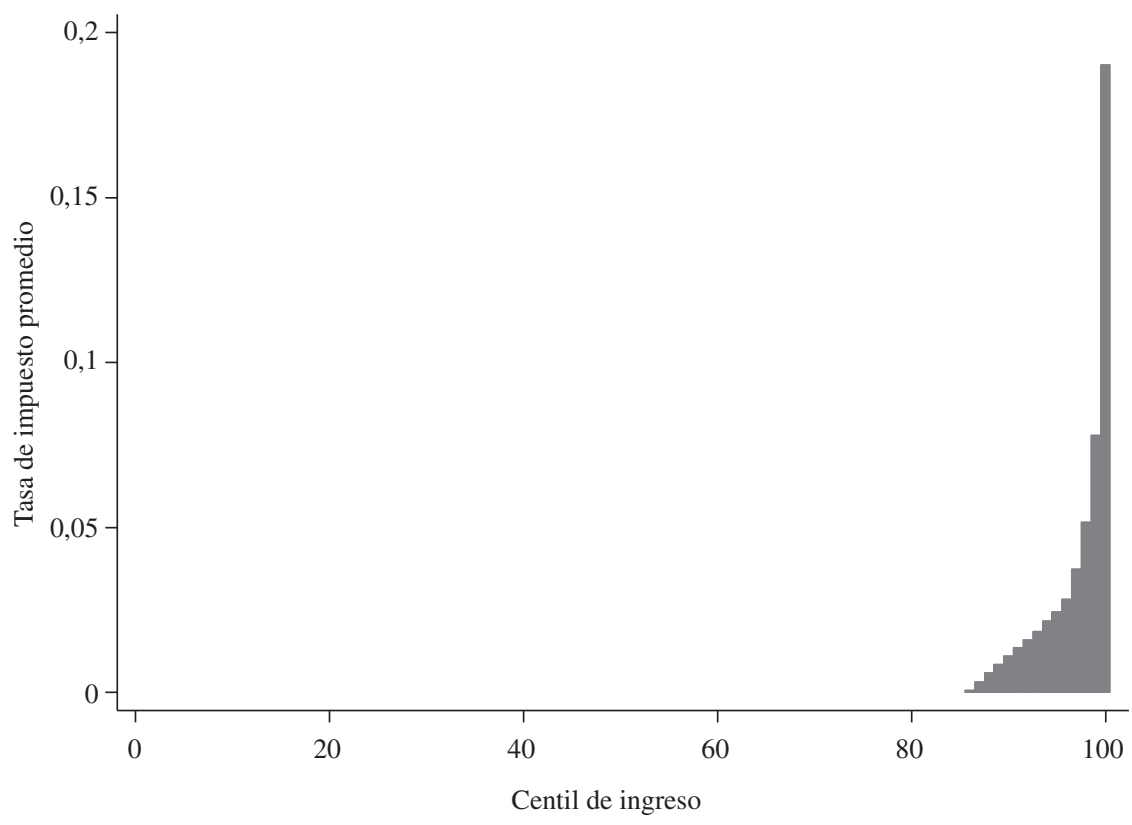

Fuente: elaboración propia sobre la base de la encuesta de Caracterización Socioeconómica Nacional (CASEN) de 2003.

GRÁFICO 9

Tasa de impuesto promedio según centil de ingreso con autorreporte de intereses y dividendos y tasa de impuesto promedio positiva

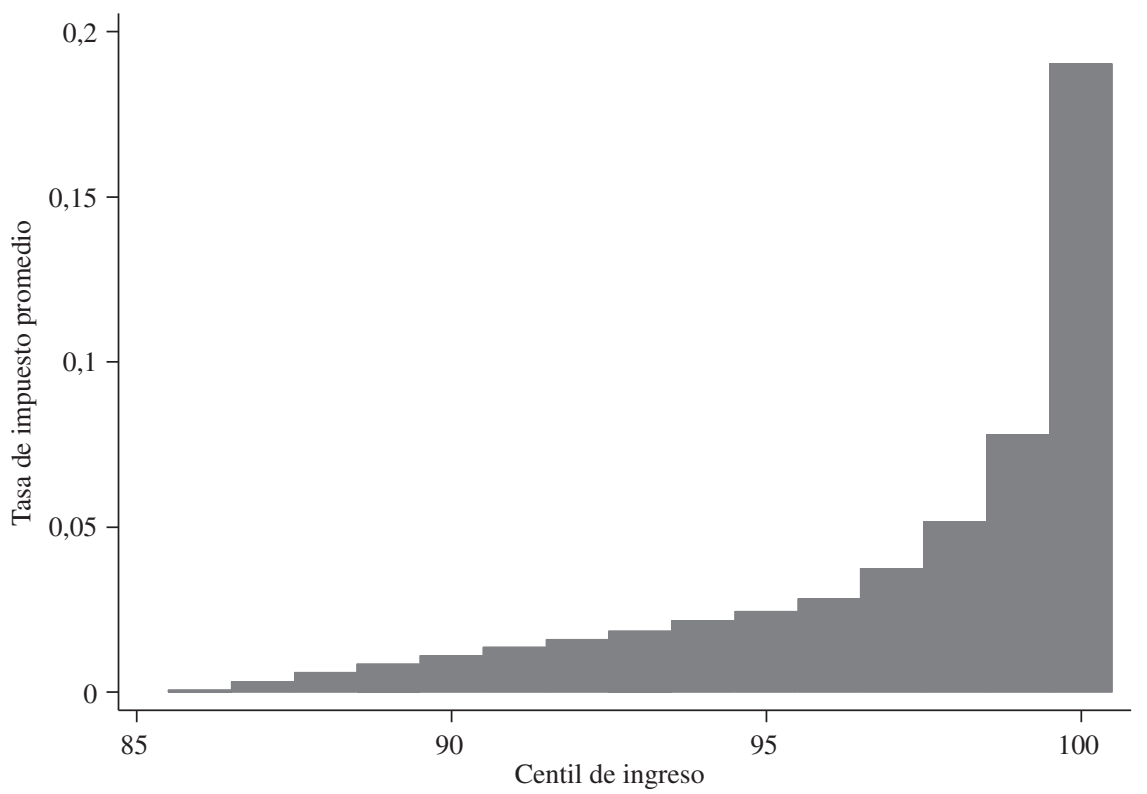

Fuente: elaboración propia sobre la base de la encuesta de Caracterización Socioeconómica Nacional (CASEN) de 2003. 
GRÁFICO 10

Tasa de impuesto promedio según centil de ingreso con imputación de intereses y dividendos

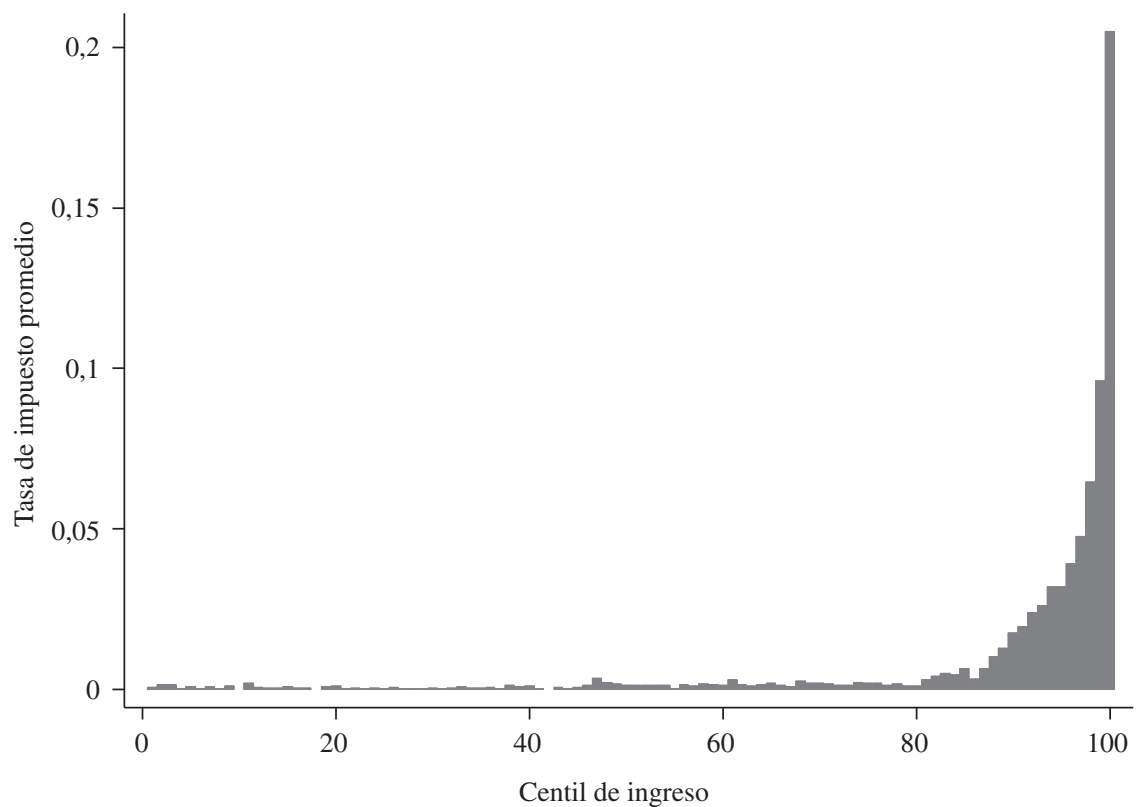

Fuente: elaboración propia sobre la base de la encuesta de Caracterización Socioeconómica Nacional (CASEN) de 2003.

GRÁFICO 11

Tasa de impuesto promedio según centil de ingreso con autorreporte de intereses y dividendos y tasa de impuesto promedio positiva

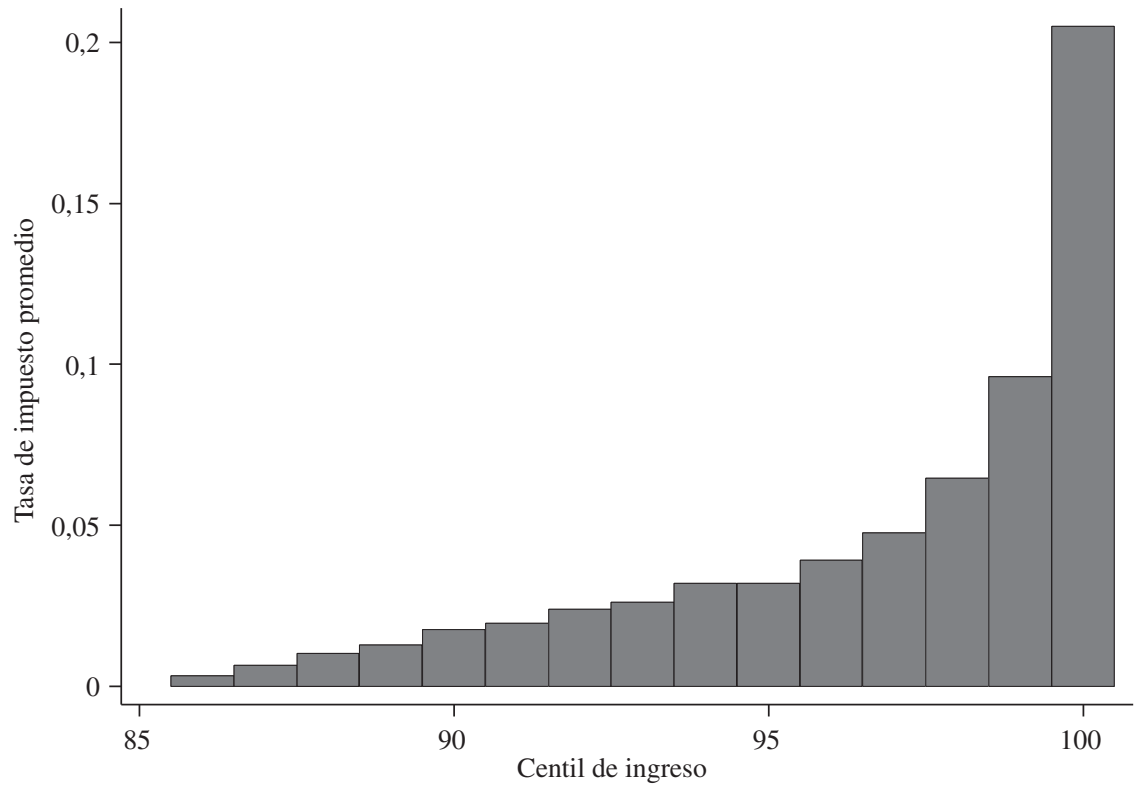

Fuente: elaboración propia sobre la base de la encuesta de Caracterización Socioeconómica Nacional (CASEN) de 2003. 
Agostini, C.A. y P. Brown (2011), "Cash transfers and poverty reduction in Chile", Journal of Regional Science, vol. 51, No 3, Wiley. (2010), "Local distributional effects of government cash transfers in Chile", Review of Income and Wealth, vol. 56, $\mathrm{N}^{\circ} 2$, Wiley.

Altshuler, R., B. Harris y E. Toder (2010), "Capital income taxation and progressivity in a global economy", TPC Working Paper, Washington, D.C., Tax Policy Center.

Bernstein, S., G. Larraín y F. Pino (2006), "Chilean pension reform: coverage facts and policy alternatives", Economía, vol. 6, N² Washington, D.C., Brookings Institution.

Cantallops, J., M. Jorrat y D. Scherman (2007), "Equidad tributaria en Chile: Un nuevo modelo para evaluar alternativas de reforma", Santiago de Chile, Comisión Económica para América Latina y el Caribe (CEPAL), inédito.

Conesa, J.C. y D. Krueger (2006), "On the optimal progressivity of the income tax code", Journal of Monetary Economics, vol. 53, $\mathrm{N}^{\mathrm{o}} 7$, Amsterdam, Elsevier.

Contreras, D. y O. Larrañaga (1999), "Activos y recursos de la población pobre en Chile", El trimestre económico, vol. 66, No 263, México, D.F., Fondo de Cultura Económica.

Davies, J.B. y M. Hoy (2002), "Flat tax rates and inequality measurement", Journal of Public Economics, vol. 84, Amsterdam, Elsevier.

DIPRES (Dirección de Presupuestos) (2009), "Informe de finanzas públicas. Proyecto de ley de presupuestos del sector público para el año 2010" [en línea] http://www.sii.cl/aprenda_sobre_impuestos/ estudios/gasto_tributario_Vfinal_2009.pdf

Engel, E., A. Galetovic y C. Raddatz (1999), "Taxes and income distribution in Chile: some unpleasant redistributive arithmetic", Journal of Development Economics, vol. 59, № 1, Amsterdam, Elsevier, junio.

Feenberg, D. y J. Poterba (1993), "Income inequality and the incomes of very high-income taxpayers: evidence from tax returns", Tax Policy and the Economy, vol. 7, J. Poterba (ed.), Cambridge, Massachusetts, міт Press.

Greene, K.V. y E.M. Balkan (1987), "A comparative analysis of tax progressivity in the United States", Public Finance Quarterly, vol. $15, \mathrm{~N}^{\circ} 4$, octubre.

Halperin, D. (2009), "Mitigating the potential inequity of reducing corporate rates", TPC Working Paper, Washington, D.C., Tax Policy Center.

Harris, B. (2009), "Corporate tax incidence and its implications for progressivity", TPC Working Paper, Washington, D.C., Tax Policy Center.

Hayes, K.J., P.L. Lambert y D.J. Slottje (1995), "Evaluating effective income tax progression", Journal of Public Economics, vol. 56, $\mathrm{N}^{\mathrm{o}} 3$, Amsterdam, Elsevier.

Jorrat, M. (2009), "La tributación directa en Chile: Equidad y desafíos", serie Macroeconomía del desarrollo, № 92 (LC/L.3094-P),
Santiago de Chile, Comisión Económica para América Latina y el Caribe (CEPAL). Publicación de las Naciones Unidas, $\mathrm{N}^{\circ}$ de venta: S.09.II.G.78.

Kiefer, D. (1984), "Distributional tax progressivity indexes", National Tax Journal, vol. 37, $\mathrm{N}^{\circ}$ 4, Washington, D.C., National Tax Association.

Kleven, H. y E.A. Schultz (2011), "Estimating taxable income responses using Danish tax reforms", EPRU Working Paper, N $^{\circ} 2011-02$, Copenhague, Universidad de Copenhague.

Lindsey, L. (1987), "Individual taxpayer response to tax cuts: 1982-1984: With implications for the revenue maximizing tax rate", Journal of Public Economics, vol. 33, $\mathrm{N}^{\circ} 2$, Amsterdam, Elsevier.

Metcalf, G.E. (1999), "A distributional analysis of an environmental tax shift”, National Tax Journal, vol. 52, No 4, Washington, D.C., National Tax Association.

MIDEPLAN (Ministerio de Planificación y Cooperación) (2010a), "Distribución del ingreso, Encuesta CASEN 2009" [en línea]: http://www.ministeriodesarrollosocial.gob.cl/casen2009/ distribucion_ingreso_casen_2009.pdf

(2010b), "Principales resultados de pobreza CASEn 2009" [en línea] http://www.ministeriodesarrollosocial.gob.cl/casen2009/

Oficina de Presupuesto del Congreso (1988), The Effects of Tax Reform on Tax Expenditures, Washington, D.C., U.S. Government Printing Office.

Seetharaman, A. y G.S. Iyer (1995), “A comparison of alternative measures of tax progressivity: the case of the child and dependent care credit", The Journal of the American Taxation Association, vol. 17, $\mathrm{N}^{\mathrm{o}} 1$, American Taxation Association.

Slemrod, J. (2007), "Cheating ourselves: the economics of tax evasion", Journal of Economic Perspectives, vol. 21, No 1, Nashville, Tennessee, American Economic Association.

(1996), "High-income families and the tax changes of the 1980's: the anatomy of behavioral response", Empirical Foundations of Household Taxation, M. Feldstein and J. Poterba (eds.), Cambridge, Massachusetts, National Bureau of Economic Research.

Slemrod, J. y J. Bakija (2001), "Does growing inequality reduce tax progressivity? Should it?", Inequality and Tax Policy, K. Hassett y R.G. Hubbard (eds.) Washington, D.C., The AEI Press for the American Enterprise Institute.

Slemrod, J. y S. Yitzhaki (2002), "Tax avoidance, evasion, and administration", Handbook of Public Economics, Alan J. Auerbach y Martin S. Feldstein (eds.), vol. 3, Amsterdam, Elsevier.

Suits, D. (1977), "Measurement of tax progressivity", American Economic Review, vol. 67, № 4, Nashville, Tennessee, American Economic Association.

Superintendencia de Pensiones (2003), "The Chilean Pension System" [en línea] http://www.safp.cl/573/article-3523.html. 